
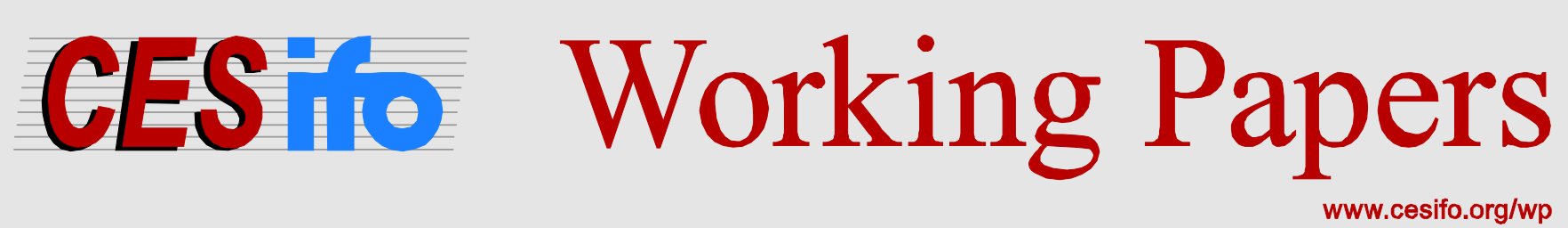

\title{
Patent Breadth in an International Setting
}

\author{
Eric Bond \\ Ben Zissimos
}

CESIFO WORKING PAPER NO. 6411

CATEGORY 8: TRADE POLICY

MARCH 2017

An electronic version of the paper may be downloaded

- from the SSRN website: Www.SSRN.com

- from the RePEc website: $\quad$ www.RePEc.org

- from the CESifo website: www.CESifo-group.org/wp 


\title{
Patent Breadth in an International Setting
}

\begin{abstract}
We examine the Nash equilibria of a game where two national governments set patent breadth strategically. Broader patents make R\&D more attractive, but the effect on static efficiency is nonmonotonic. In a North.South model, where only the North can innovate, harmonization of patent breadth lowers welfare relative to the Nash equilibrium. When both countries can innovate, harmonization toward narrower patent breadth may raise world welfare.
\end{abstract}

JEL-Codes: F020, F130, O300, O310, O320.

Keywords: coordination, innovation, patent breadth, patent race, R\&D.

Eric Bond

Department of Economics

Vanderbilt University

USA - 37235-1819 Nashville TN

eric.bond@vanderbilt.edu
Ben Zissimos

Business School

University of Exeter

United Kingdom - EX4 4ST Exeter

b.zissimos@exeter.ac.uk

This draft: October 24th, 2016

We would like to thank Miguel Ballester, Elias Dinopoulos, Edwin Lai, Jee-Hyeong Park, Katheryn Russ, Tobias Seidel, Alan Spearot, Stefano Trento and Xuebing Yang for useful comments and conversations about this paper. We also appreciated comments by seminar participants at Universitat Autònoma de Barcelona, the Econometric Society Meetings at IMPA, Rio de Janeiro, the Midwest International Meetings at the University of Iowa, the Asia Paci.c Economic Association meetings at UC Santa Cruz, a SITE Workshop at Stanford, and the World Congress of the Econometric Society in Shanghai. Financial support by the Center for the Americas at Vanderbilt University is gratefully acknowledged. 


\section{Introduction}

At its most basic, patent breadth determines how different a competing product must be in order to avoid infringing on a patent that has already been granted. Narrower patents make it easier for competitors to enter the market and thus reduce the profitability of a given patent, but benefit consumers by making the market more competitive. The value of patent protection provided by national patent laws will thus depend on the breadth of patent protection provided as well as its length. Patent breadth is reflected in patent laws in two ways: the size of the innovative step that is required in order for a new product to receive a patent and the extent to which an imitating product must differ from a patented product in order to avoid infringing on the patent. O'Donoghue et al (1998) refer to the former concept as leading patent breadth and the latter as lagging patent breadth. The Trade-Related Intellectual Property Rights (TRIPS) agreement has made an effort to harmonize the length of patent protection by setting minimum patent lives for members of the World Trade Organization (WTO). However, the agreement did not attempt to harmonize patent breadth across countries. Part of the reason is that the implications of such harmonization remain poorly understood.

The purpose of this paper is to study the strategic interaction between national governments over how they set patent breadth, and to identify the potential gains from harmonization of patent breadth across countries. Falvey and Foster (2006) explain how governments interact strategically over patent breadth. "Developed countries with many potential innovators have tended to opt for relatively strong IPR (intellectual property rights) systems. With R\&D spending concentrated in a handful of the world's richest countries, genuinely innovative activities are limited in most developed and developing countries. The majority of countries in the world have taken a different approach, providing only weak IPR protection, if any, as a way of allowing rapid diffusion of knowledge through imitation as a significant source of technological development." We interpret the adoption of weak IPR protection by some governments, equivalently narrow patent breadth, as a strategic response to the adoption of relatively strong IPR protection by others. The strategic use of patent breadth can also be illustrated in the case of Japan, where a narrow interpretation of patent breadth in both the leading and lagging dimensions was an intentional development strategy (Maskus and McDaniel 1999). Our aim is to provide a framework through which this kind of strategic interaction between governments over patent breadth can be understood. 
The breadth of patent protection provided by a country depends on both the language of the laws and the manner in which they are interpreted by courts. One manifestation of a country's choice of patent breadth is the extent to which it applies the 'doctrine of equivalents.' The doctrine of equivalents extends the protection from a patent beyond the literal claims in the patent by allowing a patent holder to claim infringement if the competing product provides essentially the same service or outcome. In the United States, the doctrine of equivalents has evolved to a three pronged test in which infringement occurs if the process or product in question (i) performs the same function (ii) in the same way (iii) to obtain the same result as that of the patent holder. ${ }^{4}$ Ralston (2007) notes that while Germany has adopted patent breadth similar to that of the US through its application of the doctrine of equivalents, Japan and the United Kingdom have chosen a narrower patent breadth by not applying a doctrine of equivalents. Instead, they have relied on a literal interpretation of the patent to determine when infringement occurs.

These differences in the application of the doctrine of equivalents are reflected in the outcomes of some patent infringement cases, where a claim of infringement may be upheld in a country with broad patent protection but not in another country with narrower patent protection. A case in point is Improver Corporation v Remington (1990)..$^{5}$ Improver Corporation had developed a depilatory device for women called the Epilady that used a helical spring to remove unwanted hair. In light of the success of the Epilady, Remington entered the market with a similar device that used a rubber rod in place of the helical spring. Improver Corporation then sued Remington for infringement. The German court found that Remington's product infringed because the substitution of a rubber rod would have no material effect on the way that the product operated and that an expert in the field would have recognized that the rubber rod would have no material effect. While the UK court agreed with these two points, it also found that there was no infringement because an expert in the field would have recognized from the language in the patent that the helical spring was an essential part of the patent. By adding this third requirement for a finding of equivalence, the UK patent system requires a more literal interpretation of the claims in the patent which substantially narrows the protection to patent holders.

Patent breadth in the US is limited by the requirement that the doctrine of equivalents

\footnotetext{
${ }^{4}$ Union Paper-Bag Machine Co. v. Murphy, 97 U. S. 120, 97 U. S. 125.

${ }^{5}$ The discussion in this section draws on Hatter (1994-5) and Bonitatibus (2001-2).
} 
be applied to each claim in the patent. For example, it was established in Abbott v Sandoz that a patent to produce a product using a particular process is not infringed by a competitor who produces the product using a different process (Macedo 2009). The differing process is not required to be superior to the process in the patent, but only required to be one that was not contained in prior art. This provides room for imitators to compete with new products if they can 'invent around the patent,' developing an alternative process that does not infringe on the existing patent. Thus, the manner in which a country applies the doctrine of equivalents has implications for both leading and lagging patent breadth.

In our analysis of patent breadth, we consider a two country model in which two firms (one in each country) are competing in a patent race to develop a new product. The loser must decide whether or not to produce an 'imitation' that competes with the patented product (an option that is available whether or not it participates in the patent race). We model patent breadth along the lines of the seminal work of Klemperer (1990), who identifies patent breadth as the 'distance' that potential competitors must locate from the patented product. Products that are a further distance from the patented product are less attractive to consumers, and thus have a smaller impact on the profits of the patent holder. It will then be easier for a competitor to innovate around a patent and take market share from the patent holder when the government provides narrow patent protection. Moreover, an imitation that is at a given distance from the patented product may infringe on a patent in a country where protection is relatively broad but not in another country where it is narrower, as in the case of Improver Corporation v Remington (1990) discussed above. The profitability of the imitation depends on the patent breadth in each country. The narrowest possible patent breadth will allow the imitating firm to produce a product that is a perfect substitute for the innovation, whereas a very broad patent will preclude entry by the imitator because the imitation is not valued at all by consumers.

Although in our model the effect of patent breadth on profits of the patent holder is similar to that of Klemperer, our analysis differs in several important ways. Klemperer analyzes a closed economy model, whereas we consider a two country model that highlights strategic interactions between governments. We consider a single imitator, rather than a competitive fringe. To capture the presence of entry barriers, we choose a market structure in which the potential imitator has market power. We do this on the basis that in practice the number of firms capable 
of duplicating a product from the information available in a patent filing may be limited. ${ }^{6}$ Also, the presence of large marketing costs may give firms with existing brand names a significant advantage over new entrants, even though the products are very similar. ${ }^{7}$ Finally, we treat the patent length as exogenously given. ${ }^{8}$

As with the more familiar concept of patent length, the choice of patent breadth involves a trade-off to each government in terms of national welfare. Increasing patent breadth increases the expected profit to a firm from innovation and thus makes it more likely that there is a successful innovation that increases welfare. We capture the effect of differences in levels of innovative ability across countries by allowing for differences across countries in the probability that the domestic firm wins the patent race. Our analysis reveals that the effect on static welfare from increasing patent breadth is not to monotonically decrease welfare in the duopoly case. Making patents broader raises industry output and raises the innovator's price, potentially raising welfare, but it does so by shifting sales away from the innovator towards the imitator. Since an imitator's product is less attractive to consumers, this shift in sales results in an ambiguous effect on static welfare. It is this set of welfare effects that drives the strategic policy interactions between governments and explains why equilibrium outcomes are different for patent breadth to those that arise from strategic interaction over patent length.

To highlight the role of a country's stage of development (and hence its firm's likelihood of winning a patent race), we focus on two cases: a North-South model in which the Southern firm has a zero probability of innovating and a North-North model where each country's firm has the same probability of successful innovation. Our results in the North-South model indicate that the South will choose the minimum level of patent breadth required to ensure entry by the innovating firm, whereas the North will choose the maximum level of breadth. This characterization of equilibrium captures the strategic interaction between governments over patent breadth described by Falvey and Foster (2006) above. Interestingly, we also show that harmonization of patent breadth would reduce world welfare in the North-South case.

\footnotetext{
${ }^{6}$ Bond and Saggi (2014) note that in a number of cases where compulsory licenses have been issued for patented drugs, the licensees have struggled to produce products of acceptable quality.

${ }^{7}$ This holds for the case of over-the-counter pain relief products, where brand name products continue to hold significant market shares even though patents have expired and the production processes are well known. In the case of ibuprofen, for example, Advil holds more than $50 \%$ of the market.

${ }^{8}$ Since leading patent breadth will affect the useful life of the product by affecting the time at which the product is replaced by a superior product, our analysis can also be interpreted as treating the leading patent breadth as given.
} 
Our framework can also be used to understand why the extent of intellectual property protection might vary across countries that are at a similar stage of development. To do this, we characterize an asymmetric equilibrium in our North-North model. In this equilibrium, one country sets patent breadth at a positive level while the other free rides by providing more limited protection or even none at all. This type of asymmetric equilibrium rationalizes the asymmetry in patent protection across the industrialized countries during the late 19th and early 20th Centuries. While Britain, Germany, France and the US had already introduced patent laws by the early 19th Century, in 1869 the Netherlands repealed its very poor patent law of 1817, while Switzerland introduced an 'extremely rudimentary' patent law in 1888 and did not have a comprehensive patent system until 1907. Schiff (1971) discusses how the Netherlands and Switzerland were able to free ride on the patent protection provided by the other industrialized countries, before eventually yielding to their pressure to coordinate through the International Union for the Protection of Industrial Property. Thus, although our framework is highly stylized, it provides a rationale for international interactions over intellectual property protection that were until this point difficult to make sense of.

In the North-North model, harmonization would raise world welfare but in a surprising way. Under certain circumstances there is the familiar incentive to reach an agreement that simultaneously raises patent breadth in all countries. The novel idea which we will bring to light is that there may alternatively be an incentive for such agreements to impose a maximum allowable patent breadth instead. This addresses a hitherto puzzling situation that has been observed at the European Patent Office (EPO). Not only has the EPO upheld patents that some member countries refused to grant, an example of coordination across Europe that raises the breadth of patent protection. But the EPO has also revoked patents that have been granted by member countries, an example of coordination that reduces patent breadth. ${ }^{9}$

Our results complement those obtained on the setting of optimal patent length in the literature on international trade and the protection of intellectual property. Deardorff (1991) uses the classic model of Nordhaus (1969) to examine the impact of extending patent protection in technology importing countries, and identifies a trade-off between a worsening terms of trade and a higher world rate of innovation. Grossman and Lai (2004) solve for the non-cooperative equilibrium in the setting of patent length (or equivalently the strictness of enforcement) when

\footnotetext{
${ }^{9}$ The Economist (2009) discusses examples of such occurrences.
} 
governments set policy to maximize national welfare and the industry structure is one of monopolistic competition. They find that patent protection in the non-cooperative equilibrium will be lower in countries that do less $\mathrm{R} \& \mathrm{D}$, and that the non-cooperative equilibrium will involve patent lengths that are too short relative to the cooperative level. The results for both our North-South and North-North models differ in that Nash equilibrium may have either more or less R\&D than the optimal level. In both models this feature rests on the non-monotonic effect of increasing patent breadth on static welfare mentioned earlier. In our North-North model we also have the possibility of asymmetric equilibria wherein similar countries have different levels of protection in the Nash equilibrium.

Using a closed economy 'quality ladders' endogenous growth model, Chor and Lai (2014) examine the trade-offs faced by a government in the setting of the leading patent breadth. Extending patent breadth makes a successful innovation more profitable, but it also raises the hurdle to obtaining a patent. They characterize the welfare maximizing patent breadth, and show that it is less than the breath that maximizes the rate of innovation. Chu and Peng (2010) analyze the optimal patent breadth in a two country quality ladders model where patent breadth serves as a shift parameter on the profits of the innovator engaged in Bertrand competition with potential imitators. They find that in general the country with less innovative ability will choose narrower patents.

The paper proceeds as follows. Section 2 sets out the basic model and defines the patentbreadth game. Sections 3 and 4 characterize equilibrium for the North-South and North-North models respectively. The scope for international coordination over patent breadth is considered in each section. Conclusions are drawn in Section 5.

\section{The Model}

We consider a model in which the governments of two countries, referred to as home and foreign, set the breadths of patent protection for sales of a newly developed product in their respective national markets. Two firms, one in each country, compete to develop a new product under the constraints imposed by the patent breadths. In this section we set out the basic elements of the model, which will allow us to characterize consumer preferences and firm technology, and describe the 3 -stage patent breadth game. 
In order to participate in the competition to develop a new product, a firm must pay a fixed cost of $\mathrm{R} \& \mathrm{D}, r$, which is assumed to be the same for both firms. R\&D results in the successful development of a new product with probability $\theta \in[0,1]$ for the home firm and $\theta^{*} \in[0,1]$ for the foreign firm (foreign variables are denoted with a "*”). Without loss of generality, assume $\theta \geq \theta^{*} .{ }^{10}$ In the event that only one firm makes an innovation, it receives the patent on the product. If both firms innovate successfully, each firm receives the patent with a probability of $1 / 2$. If both engage in $R \& D$, the probability of obtaining a patent is $\theta\left(1-\theta^{*} / 2\right)$ for the home firm and $\theta^{*}(1-\theta / 2)$ for the foreign firm. We denote the innovation (that receives the patent) by subscript- $n$.

Once the patent has been awarded, the innovator can produce the good at a constant marginal cost, which we normalize to zero. The other firm can develop a competing product that imitates the innovator's good as long as it does not infringe on the patent. The imitation will also have a marginal production cost of zero. We will assume that the fixed cost of developing the imitation is arbitrarily small, and that a firm can imitate whether or not it chose to engage in $R \& D$. If the imitator does not engage in the initial stage $R \& D$, then it free-rides on the $R \& D$ activity of the innovating firm in the event a new product is developed. The imitation is denoted by subscript- $m .^{11}$

Preferences of the home consumer are expressed as follows:

$$
u\left(q_{m}, q_{n} ; w\right)=e\left(q_{n}+q_{m}\right)-\frac{1}{2}\left(q_{n}+q_{m}\right)^{2}-w q_{m}+x .
$$

In this equation, $q_{n}$ is consumption of the innovation, $q_{m}$ is consumption of the imitation, $x$ is consumption of all other goods in the home market, and $w$ is the distance in product space of the imitation from the preferred location of the innovation. In the absence of patent protection, which is equivalent to the narrowest patent breadth of $w=0$, an imitator would choose to produce a product that embodied all of the attributes of the innovator's product and hence be of equal value to consumers. The government, by choosing a patent breadth of $w>0$, restricts how close the imitator's product can be to that of the innovator without infringing on the innovator's patent. For values of $w$ sufficiently large, the product attribute that consumers

\footnotetext{
${ }^{10}$ For simplicity we assume that $r, \theta$ and $\theta^{*}$ are parametric. Essentially the same model characteristics would be obtained, at the cost of greater complexity, if $\theta$ and $\theta^{*}$ were made to depend on $r$.

${ }^{11}$ We assume that once a product has been developed and patented, the knowledge acquired from R\&D becomes a public good that is available to the other firm even if it did not undertake $R \& D$. So in a given market, the asymmetry between the firms in competition results from the constraint on how similar an imitation is allowed to be to the innovation by the breadth of the patent.
} 
value in the innovation will be so much less effective or desirable in the imitation that it is worthless to consumers. ${ }^{12}$ Preferences in the foreign country are assumed to be identical to those at home, although the foreign choice of patent breadth, $w^{*}$, may differ from that at home. $^{13}$

We capture the dynamics of the problem as a three stage game. In the first stage the governments simultaneously choose patent breadth, $\left(w, w^{*}\right)$. In the second stage, the home and foreign firms choose whether or not to undertake R\&D. This sequencing seems reasonable since the process of government policy formation over patent law is usually more unwieldy than firms' R\&D decision making. We denote the home firm's choice of actions by $a \in\{d, f\}$, where $d$ represents 'development' (i.e. incurring the cost $r$ ) and $f$ represents 'free riding' (or more generally no investment in $\mathrm{R} \& \mathrm{D})$. The foreign action choice $a^{*}$ is defined similarly. In the event that $\mathrm{R} \& \mathrm{D}$ is successful at developing a new product, a patent is awarded to the innovator. In stage 3 , the innovator and imitator compete as Cournot duopolists in segmented markets. If R\&D is unsuccessful, no production occurs. We solve this problem by backward induction.

\subsection{The Production Stage}

At the third stage, the roles of innovator and imitator have been determined by the patent award (assuming a successful innovation has been made) and $\mathbf{w}=\left(w, w^{*}\right)$ is given by the first stage government decisions. We make the standard segmented market assumption, so firms compete on a market-by-market basis. Due to our symmetry assumptions, the national identity of the innovating firm (home or foreign) does not matter for now. ${ }^{14}$ From (1), the inverse demand function in the home market for $n$ and $m$ will be $p_{n}=e-q_{n}-q_{m}$ and $p_{m}=e-q_{n}-q_{m}-w$

\footnotetext{
${ }^{12}$ For tractability we are taking a reduced form approach to modelling patent breadth. In a structural model, we would still think of patent breadth as setting an upper bound on the embodiment of an innovative element of the patented product as we do here. But we would also allow for the possibility that the imitator could produce a product that embodied less of the innovative element than stipulated by $w$. Under reasonable conditions, it could then be shown that the imitating firm would maximize profits by maximizing the innovative element in its product up to the limit imposed by the patent breadth, $w$. This would be equivalent to thinking of patent breadth as limiting the quality level of the imitation relative to the innovation, and the imitating firm maximizing profits by setting a quality level that is bound from above by the level of $w$.

${ }^{13}$ Differentiation across another product element such as color or design may be captured by extending (1) to the form $u=e\left(q_{n}+q_{m}\right)-\frac{\gamma}{2}\left(q_{n}+q_{m}\right)^{2}-\frac{1-\gamma}{2}\left(\left(q_{n}\right)^{2}+\left(q_{m}\right)^{2}\right)-w q_{m}+x$, where $\gamma \in[0,1]$ is a parameter that determines substitutability between the innovation and the imitation in the element not covered by the patent. We have carried out all of the analysis for this extended functional form and it makes little difference to our results, so we will not elaborate further on this in the paper.

${ }^{14}$ In our setting, the mode of market entry by the imitator does not matter either. This could be by licensing, exports or foreign direct investment. We will abstract here from any possible variation in the costs associated with different modes of entry by the imitator.
} 
respectively. ${ }^{15}$ Firm profits from the home market will be $\pi_{n}=p_{n} q_{n}$ and $\pi_{m}=p_{m} q_{m}$. Outputs for the foreign market, $\left\{q_{n}^{*}, q_{m}^{*}\right\}$ are determined similarly. It is then straightforward to solve for the Nash equilibrium output and profit levels. Throughout the paper, a "^" over a variable denotes its value in Nash equilibrium.

Lemma 1 For $w \leq w_{\max }=e / 2$, the Nash equilibrium output and price levels are given by:

$$
\hat{q}_{n}(w)=\frac{e+w}{3} ; \hat{q}_{m}(w)=\frac{e-2 w}{3} ; \hat{p}_{n}(w)=\frac{e+w}{3} ; \hat{p}_{m}(w)=\hat{p}_{n}-w .
$$

For $w>w_{\max }$, output levels are:

$$
\hat{q}_{n}=\frac{e}{2} ; \hat{q}_{m}=0
$$

Firm profits in equilibrium are:

$$
\hat{\pi}_{i}(w)=\left(\hat{q}_{i}(w)\right)^{2} \text { for } i \in\{n, m\}
$$

An increase in patent breadth makes the imitation less attractive to consumers, leading to a shift of output and profits from the imitator to the innovator. For $w \geq w_{\max }$, patent protection is sufficiently broad that it deters production by the imitator. Due to the assumption of identical demand functions across markets, the results of Lemma 1 also characterize outcomes in the foreign market. The global profits of a firm are expressed as

$$
\Pi_{i}(\mathbf{w})=\hat{\pi}_{i}(w)+\hat{\pi}_{i}^{*}\left(w^{*}\right) \text { for } i=m, n
$$

Total industry output in the home market will be $\hat{Q}(w)=\hat{q}_{n}(w)+\hat{q}_{m}(w)=(2 e-w) / 3$, which is decreasing in patent breadth. Since $p_{n}=p_{m}+w$ in any equilibrium where imitated goods are consumed, consumer surplus will be a function of the industry output, $S(Q)=\frac{1}{2} Q^{2}$. The following result, which will be useful in the analysis below, summarizes the effect of patent breadth on industry profits and social welfare in a given market.

\footnotetext{
${ }^{15}$ Because the fixed cost of developing a new product is arbitrarily small, an imitator develops two imitations: one tailored to $w$ and one to $w^{*}$. If product development were more costly then an imitator might only develop a single good, and have to decide whether to tailor it to $w$ or $w^{*}$. Introducing costs of developing a new imitating product increases the number of cases to be considered, but does not change the basic incentives of the countries regarding patent breadth. Therefore, we have adopted the assumption of costless imitation to simplify the analysis.
} 


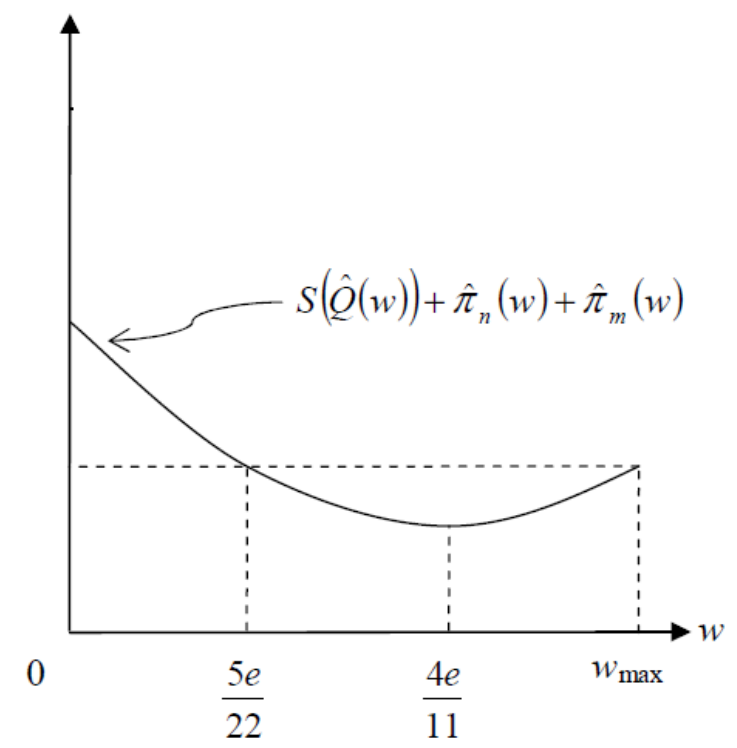

Figure 1: Total Surplus at Home as a Function of Patent Breadth

Lemma 2 Assume $w \in\left[0, w_{\max }\right]$.

(a) The Nash equilibrium industry profit from sales in the home market, $\hat{\pi}_{n}(w)+\hat{\pi}_{m}(w)$, is strictly convex in $w$. Joint profits are minimized at $w=e / 5$ and maximized at $w_{\max }$.

(b) The sum of consumer and producer surplus in the home market, $S(\hat{Q}(w))+\hat{\pi}_{n}(w)+\hat{\pi}_{m}(w)$, is strictly convex in $w$ and is minimized at $w=\frac{4 e}{11}$. The sum of consumer and producer surplus for $w<\frac{5 e}{22}$ exceeds that at $w=w_{\max }$.

The proof is in the Appendix. The intuition behind Lemma 2 is as follows. Starting from any $w \in\left(0, w_{\max }\right]$, making patent breadth narrower will raise industry output and reduce the innovator's price, which potentially raises total surplus, $S(\hat{Q}(w))+\hat{\pi}_{n}(w)+\hat{\pi}_{m}(w)$, but it does so by shifting sales from the innovator to the imitator. Since the imitator's product is less attractive to consumers for any $w>0$, this shift in sales results in an ambiguous effect on total surplus. As illustrated in Figure 1, in the neighborhood of $w_{\max }$ the difference in value to the consumer between the imitation and the innovation is sufficiently large that the increased competition resulting from a reduction in $w$ actually reduces total surplus. When the gap between the attractiveness of products is sufficiently small, however, the narrowing of patent breadth must raise total surplus. For total surplus to be above the level associated with monopoly, patent breadth must be no greater than $w=\frac{5 e}{22}$. A similar result holds for the foreign market. 
The features of the home market surplus function identified in Lemma 1 and Figure 1 play a central role in our analysis. Although the specific cutoff values reflect our functional form assumptions, we show in the Appendix that the properties that surplus is convex in $w$, maximized and decreasing in $w$ at $w=0$, and increasing at $w=w_{\max }$ hold for much more general settings. ${ }^{16}$

\subsection{The R\&D and Patent Breadth Decisions}

We will focus on two special cases in our analysis of the model. The first, which we refer to as the North-South model, assumes that $\theta>0$ and $\theta^{*}=0$. The foreign firm has no possibility of innovating in this case so the only question at the $R \& D$ stage is whether patent protection is sufficiently broad worldwide to result in the home firm undertaking R\&D. This case emphasizes the difference in incentives between countries in setting patent breadth, which arises because the Northern government knows that its firm will always be the innovator and the Southern government that its firm will be the imitator. The second case, which we refer to as the NorthNorth model, assumes that $\theta=\theta^{*}>0$. In this case the equilibrium at the R\&D stage could involve a patent race between the two firms, with both engaging in $R \& D$, if patent protection is sufficiently broad worldwide. The objective functions of the home and foreign governments will be symmetric in this case, since each country's firm has the same probability of being the innovator. This structure will allow us to explore whether the patent breadth game can have multiple equilibria, one involving a patent race and one not. We examine the game for each of these cases in turn.

\section{Equilibrium in the North-South Model}

Since the foreign (Southern) firm cannot be a successful innovator, its optimal action will necessarily be to choose free riding on home firm innovations, $a^{*}=f^{*}$. The expected profit of the home firm will be $\psi\left(d, f^{*}, \mathbf{w} ; r\right)=\theta \Pi_{n}(\mathbf{w})-r$ if it engages in $\mathrm{R} \& \mathrm{D}$, and $\psi\left(f, f^{*}, \mathbf{w} ; r\right)=0$ if it does not. The equilibrium at the second stage will thus involve R\&D by the home firm if and only if $\psi\left(d, f^{*}, \mathbf{w} ; r\right) \geq 0$. Since profits are increasing in patent breadth in each mar-

\footnotetext{
${ }^{16}$ The discussion in the Appendix demonstrates two things. First, the property that total surplus is decreasing in $w$ at $w=0$ only requires the standard condition for stability of Cournot-Nash equilibrium. Second, the property that, approaching $w_{\max }$ from below, total surplus is increasing in $w$ requires only that quantities $q_{m}$ and $q_{n}$ are strategic substitutes.
} 


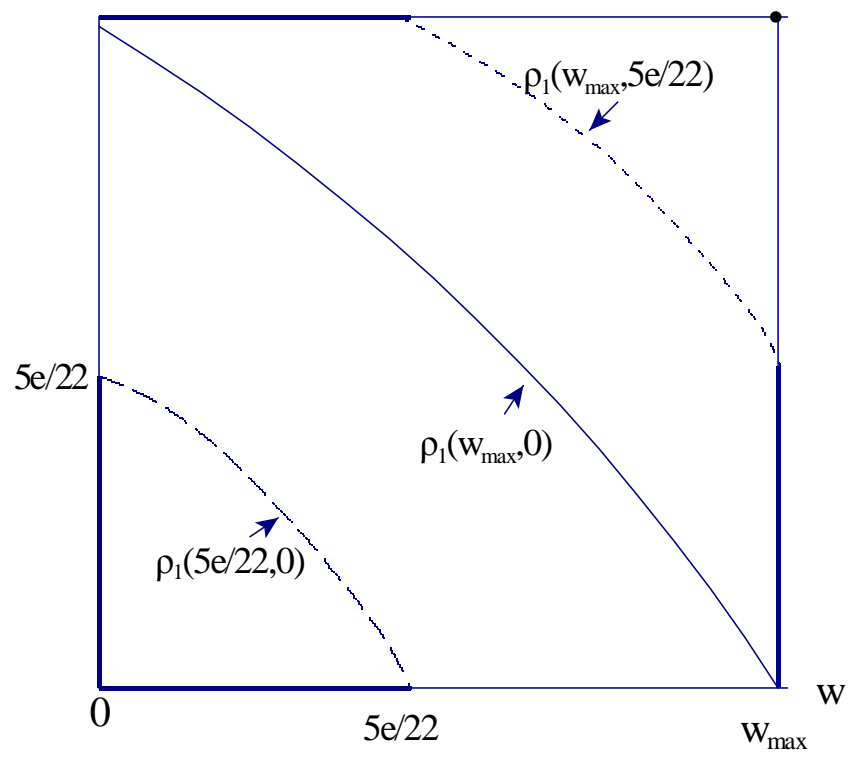

Figure 2: Equilibrium in the North-South Model

ket, there will be a unique value of $r$ satisfying $\psi\left(d, f^{*}, \mathbf{w} ; r\right)=0$, which we denote by $\rho_{1}(\mathbf{w})$. The values of $\mathbf{w}$ at which $\rho_{1}(\mathbf{w})=r$ represent the minimum overall patent breadth protection required to induce $\mathrm{R} \& \mathrm{D}$ by the home firm for given $r$. Figure 2 illustrates the $\rho_{1}(\mathbf{w})$ loci for three values of $r$ that will play a critical role in the results below: $\rho_{1}\left(\frac{5 e}{22}, 0\right), \rho_{1}\left(w_{\max }, 0\right)$ and $\rho_{1}\left(w_{\max }, \frac{5 e}{22}\right)$. If $r=\rho_{1}\left(w_{\max }, 0\right)$, for example, then the governments must set a combination of patent breadths $\mathbf{w}$ that lies on or above the $\rho_{1}\left(w_{\max }, 0\right)$ locus in order for the home firm to expect to make a profit from undertaking $\mathrm{R} \& \mathrm{D}$. The $\rho_{1}(\mathbf{w})$ locus is negatively sloped and concave to the origin due to the properties of the profit functions established in Lemma 1. Since the quantity choices of the firms are invariant for $w \geq w_{\max }$ by Lemma 1, we can restrict attention to $\mathbf{w} \in W \equiv\left[0, w_{\max }\right] \times\left[0, w_{\max }\right]$ without loss of generality. Increases in $r$ result in a rightward shift in the $\rho_{1}(\mathbf{w})$ locus. It may also be helpful to note the location of two loci that are not shown in Figure 2 to avoid clutter. The $\rho_{1}(0,0)$ locus goes through the origin and the $\rho_{1}\left(w_{\max }, w_{\max }\right)$ locus goes through the top right hand corner of $W$.

We now turn to the choice of patent breadth in the first stage. Home country welfare, $\tilde{v}$, is given by the sum of the innovating firm's profits in the two markets and consumer surplus at 
home when evaluated at the Nash equilibrium output levels:

$$
\tilde{v}(\mathbf{w} ; r)=\left\{\begin{array}{cc}
\theta\left(\Pi_{n}(\mathbf{w})+S(\hat{Q}(w))\right)-r & \text { for } \psi\left(d, f^{*}, \mathbf{w} ; r\right) \geq 0 \\
0 & \text { for } \psi\left(d, f^{*}, \mathbf{w} ; r\right)<0
\end{array}\right.
$$

Broader patent breadth will shift profits from the foreign imitator to the home innovator, while reducing consumer surplus at home. Differentiating (3) with respect to $w$ and $w^{*}$ yields

$$
\frac{\partial \tilde{v}(\mathbf{w} ; r)}{\partial w}=\frac{\theta w}{3} \geq 0, \frac{\partial \tilde{v}(\mathbf{w} ; r)}{\partial w^{*}}=\frac{2 \theta\left(e+w^{*}\right)}{9}>0 \text { for } \psi\left(d, f^{*}, \mathbf{w} ; r\right) \geq 0 .
$$

The gain in profits from increasing patent breadth dominates the loss of consumer surplus for all $w \in\left[0, w_{\max }\right)$ and $\psi\left(d, f^{*}, \mathbf{w} ; r\right) \geq 0$, so $\hat{w}\left(w^{*}\right)=w_{\max }$ in the home country. Since welfare is independent of $w$ for $\psi\left(d, f^{*}, \mathbf{w} ; r\right)<0$, setting $w=w_{\max }$ is a weakly dominant strategy for the home government. An increase in the breadth of foreign patents has a favorable spillover effect on the home country because it raises the return from innovation.

For the foreign country, welfare is the sum of imitator profits and consumer surplus in the domestic (i.e. foreign) market:

$$
\tilde{v}^{*}(\mathbf{w} ; r)=\left\{\begin{array}{cl}
\theta\left(\Pi_{m}(\mathbf{w})+S\left(\hat{Q}^{*}\left(w^{*}\right)\right)\right) & \text { if } \psi\left(d, f^{*}, \mathbf{w} ; r\right) \geq 0 \\
0 & \text { if } \psi\left(d, f^{*}, \mathbf{w} ; r\right)<0
\end{array}\right.
$$

Differentiating with respect to $w$ and $w^{*}$ yields

$$
\begin{gathered}
\frac{\partial \tilde{v}^{*}(\mathbf{w} ; r)}{\partial w^{*}}=-\frac{\theta(2 e-3 w)}{3}<0, \frac{\partial \tilde{v}^{*}(\mathbf{w} ; r)}{\partial w}=-\frac{4 \theta((e-2 w)}{9}<0 \\
\quad \text { for } \psi\left(d, f^{*}, \mathbf{w} ; r\right) \geq 0 \text { and } \mathbf{w} \in W .
\end{gathered}
$$

Making patent protection broader in the foreign country will transfer surplus from foreign consumers and the imitating foreign firm to the innovating home firm, which reduces foreign welfare. Increases in the home patent breadth will reduce foreign welfare similarly. Since foreign welfare is 0 if the home firm does not undertake $R \& D$ and is positive if the home firm does, the best response for the foreign government is the minimum value of $w^{*}$ such that $\psi\left(d, f^{*}, \mathbf{w} ; r\right) \geq 0$, which we denote by $j(w, r)$ if it exists. (We will clarify in due course the circumstances under which $j(w, r)$ exists.) In other words, the foreign government will choose the minimum patent breadth necessary to induce R\&D by the home firm.

Combining the best responses for the respective countries yields the following result. 
Proposition 1. Assume the North-South model.

(a) If $r \in\left(\rho_{1}\left(w_{\max }, 0\right), \rho_{1}\left(w_{\max }, w_{\max }\right)\right)$ then in Nash equilibrium the home government sets patent breadth $\hat{w}=w_{\max }$ and the foreign government sets $\hat{w}^{*}=j(\hat{w}, r)>0$.

(b) If $r \in\left[\rho_{1}(0,0), \rho_{1}\left(w_{\max }, 0\right)\right]$, then the home government sets patent breadth $\hat{w}=w_{\max }$ and the foreign government sets patent breadth $\hat{w}^{*}=0$ in the Nash equilibrium.

Proposition 1 can be illustrated using Figure 2. In both cases (a) and (b), the home government makes patent breadth as broad as possible to maximize the profit of its innovating firm; $\hat{w}=$ $w_{\max }$. For $r>\rho_{1}\left(w_{\max }, 0\right)$, protection in the foreign market is necessary for the home firm to have an incentive to engage in $\mathrm{R} \& \mathrm{D} ; \hat{w}^{*}=j(w, r)>0$. In this region the Nash equilibrium will be at the intersection of the $\rho_{1}(\mathbf{w})$ locus with the right boundary of $W$. For $r<\rho_{1}\left(w_{\max }, 0\right)$, maximum patent protection in the home country is sufficient to ensure R\&D is undertaken and the foreign government sets $\hat{w}^{*}=0$ so the Nash equilibrium is in the bottom corner of the right boundary of $W$. In this region of $r$, the home government chooses a higher level of protection than is necessary to ensure $R \& D$ because it wants to shift profits to its innovating firm. The Nash equilibrium of the patent breadth game in the North-South model is always on the right boundary of $W$.

This result shows that, in a non-cooperative equilibrium, the South will free ride on patent protection as long as its market is not essential for making R\&D profitable. Even when Southern patent protection is essential it will be the minimum sufficient for profitability. While we have assumed symmetric market sizes, in practice South markets are relatively small for most products in comparison with developed country markets in the North. Developing countries would thus have an incentive to provide no patent breath for most products, with the exception being products such as pharmaceuticals for the treatment of tropical diseases where the primary demand is in developing country markets. ${ }^{17}$

A natural question to ask is whether world welfare could be raised by an agreement between the home and foreign country regarding patent breadth. Assuming that lump sum transfers between countries are possible, an efficient international agreement on patent breadth will be

\footnotetext{
${ }^{17}$ Note here that we are assuming the South is able to commit to a level of patent breadth, so that the innovator would know at the time of the investment the amount of patent breath that can be expected if the $R \& D$ is successful. In a multiperiod model with ongoing $R \& D$, there would be an incentive for the South to develop a reputation for protecting innovations for products where its market is essential.
} 
one that chooses $\mathbf{w}$ to maximize world welfare,

$$
\Omega(\mathbf{w} ; r) \equiv \tilde{v}(\mathbf{w} ; r)+\tilde{v}^{*}(\mathbf{w} ; r)
$$

subject to the constraint that $\psi\left(d, f^{*}, \mathbf{w} ; r\right) \geq 0 .{ }^{18}$ Lemma 2 established that total surplus in each of the individual markets will be strictly convex in patent breadth, given that an innovation has occurred, so $\Omega$ will be strictly convex in $w$ and $w^{*}$. The following result establishes that, depending on the level of $r$, the non-cooperative equilibrium in patent breadth may involve too little patent protection (relative to the social optimum), too much patent protection, or the socially optimal amount of patent protection.

Proposition 2. Assume the North-South model.

(a) If $r \in\left(\rho_{1}\left(w_{\max }, \frac{5 e}{22}\right), \rho_{1}\left(w_{\max }, w_{\max }\right)\right)$, world welfare is maximized at $w=w^{*}=w_{\max }$. Patent breadth in the Nash equilibrium is below the world welfare maximizing level.

(b) If $r \in\left[\rho_{1}\left(\frac{5 e}{22}, 0\right), \rho_{1}\left(w_{\max }, \frac{5 e}{22}\right)\right]$, world welfare is maximized at $w=w_{\max }$ and $w^{*}=$ $j\left(w_{\max }, r\right)$. Patent breadth in the Nash equilibrium is at the world welfare maximizing level.

(c) If $r<\rho_{1}\left(\frac{5 e}{22}, 0\right)$, world welfare is maximized at $w=j(0, r)$ and $w^{*}=0$. Patent breadth in the Nash equilibrium is above the world welfare maximizing level.

The proof is in the Appendix. The intuition for this result can be obtained by referring to Figure 2. The first part of the proof shows that world iso-welfare contours are more convex than the $\rho_{1}(\mathbf{w})$ loci, so that any point on the interior of $W$ is dominated in world welfare terms by a point on the boundary that yields the same expected profits from R\&D. Therefore, the set of world welfare maximizing $\mathbf{w}$ combinations must be contained in the boundary points of $W$. However, not all points on the boundary maximize world welfare; the sets of points that do maximize world welfare are shown in bold in Figure 2. By Lemma 2b, any point on the boundary with a patent breadth choice in the interval $\left(\frac{5 e}{22}, w_{\max }\right)$ yields lower welfare than choosing the maximum patent breadth, $w_{\max }$. Since raising patent breadth will increase the expected profits of the home firm, such an increase is also feasible. Therefore, no boundary points with patent breadth in the interval $\left(\frac{5 e}{22}, w_{\max }\right)$ can be world welfare maximizing. If the $\rho_{1}(\mathbf{w})$ locus intersects the boundary

\footnotetext{
${ }^{18} \mathrm{We}$ are examining a constrained social welfare optimum in which $\mathrm{R} \& \mathrm{D}$ must be financed through patent protection. A social planner with the ability to impose lump sum taxes to finance R\&D could achieve higher welfare by using marginal cost pricing for the good. We choose the constrained optimum to focus on the distortions introduced by competition between governments, so we restrict the planner to the same instruments as available to the governments.
} 
at a point in the bold set, then that point is the world welfare maximum. If the $\rho_{1}(\mathbf{w})$ locus intersects the boundary at a point not contained in the bold set, then patent breadth in the corresponding country should be raised to $w_{\max }$ to maximize world welfare. Note that the world welfare maximum could be achieved by the foreign government setting a positive patent breadth and the home government not doing so. The home firm would still undertake R\&D but foreign consumers would be paying most of the cost. This outcome would not arise when governments are choosing policies because each government maximizes the surplus of its own consumers and firms, but the world welfare criterion does not distinguish who pays for or receives surplus. Hence the bold sections on the boundary of Figure 2 indicating the world welfare maximizing policy combinations are symmetrical.

Recall from Proposition 1 that the Nash equilibrium points are those on the right hand boundary of the box. Part (a) of Proposition 2 arises when $r$ is sufficiently high that the foreign government must choose $\hat{w}^{*}>\frac{5 e}{22}$ in the Nash equilibrium in order to induce R\&D by the home firm. In this region, the foreign government chooses a lower level of patent breadth than is socially optimal in order to make entry more profitable for its imitating firm; it chooses $\hat{w}^{*}=$ $j(\hat{w}, r)$ while the home government sets $\hat{w}=w_{\max }$ (part a of Proposition 1) and $w=w^{*}=w_{\max }$ is the social optimum. Part (c) of Proposition 2 shows that if $r$ is sufficiently low that R\&D investment will be undertaken for $w<\frac{5 e}{22}$, the Nash equilibrium patent breadth at home exceeds the socially optimal level; home chooses $\hat{w}=w_{\max }$ while the foreign government sets $\hat{w}^{*}=0$ (part b of Proposition 1) and $w=j(0, r), w^{*}=0$ corresponds to the social optimum. In this region, the desire of the home country to protect its firm by deterring entry of the foreign imitator is socially costly. For intermediate values of $r$ as identified in part (b) of Proportion 2, the Nash equilibrium coincides with a world welfare maximum.

The convexity of the world welfare contours means that the world welfare maximizing policy does not involve the harmonization of patent breath across countries in cases (b) and (c) in Proposition 2, where the zero-expected-profit condition is binding. It is efficient for consumers in one of the countries to pay for as much of the patent protection as possible, rather than spreading it evenly between countries. Clearly, lump sum transfers between countries are required to make such an agreement individually rational for both of the countries. In case (a) of Proposition 2, the world welfare maximizing solution does involve harmonization (at $w_{\max }$ ) but lump sum transfers would still be required to reach an agreement at this level. In this 
case, the $\rho_{1}(\mathbf{w})$ locus lies above the $\rho_{1}\left(w_{\max }, 0\right)$ locus and so the Nash equilibrium lies at the point where the $\rho_{1}(\mathbf{w})$ locus intersects the right boundary of $W$. So in Nash equilibrium the home government sets $\hat{w}=w_{\max }$ at the socially optimal level, but the foreign government sets $\hat{w}^{*}=j(w, r)$, which is below the social optimum. Therefore, agreeing to the social optimum for the foreign government would require a deviation from its best response for which it would need to be compensated.

\section{Equilibrium in the North-North Model}

We now turn to the analysis of the North-North model, where each firm has the same probability $\theta>0$ of successfully discovering a new product and obtaining the patent. This leads to the possibility that there are Nash equilibria in which both firms enter into a patent race, as well as equilibria in which only one firm finds it profitable to undertake R\&D. In the latter case, symmetry ensures that there be two Nash equilibria, $\left(d, f^{*}\right)$ and $\left(f, d^{*}\right)$. To provide a unique equilibrium outcome to the game for all values of $r$, we will assume that at the beginning of the second stage nature randomly selects one of the firms (with equal probability) to move first in the R\&D decision. This assumption maintains the symmetry between the home and foreign firms. ${ }^{19}$ Since the home and foreign firms are symmetric, we can derive the best-response functions by considering the decision of the home firm only.

If the foreign firm does not undertake $R \& D$ then the home firm's best response is to undertake $\mathrm{R} \& \mathrm{D}$ if $\psi\left(d, f^{*}, \mathbf{w} ; r\right) \geq 0$, as in the North-South model. If the foreign firm does undertake $\mathrm{R} \& \mathrm{D}$, the home firm expects to earn $\psi\left(f, d^{*}, \mathbf{w} ; r\right)=\theta \Pi_{m}(\mathbf{w}) \geq 0$ as an imitator if it does not enter into a patent race and $\psi\left(d, d^{*}, \mathbf{w} ; r\right)=\theta(1-\theta / 2)\left[\Pi_{n}(\mathbf{w})+\Pi_{m}(\mathbf{w})\right]-r$ from the patent race if it enters. Therefore, entry by the home firm into a patent race will be a best response to entry by the foreign firm if and only if

$$
\beta(\mathbf{w} ; r) \equiv \theta\left(1-\frac{\theta}{2}\right) \Pi_{n}(\mathbf{w})-\frac{\theta^{2}}{2} \Pi_{m}(\mathbf{w})-r \geq 0 .
$$

So $\beta(\mathbf{w} ; r)$ represents the home firm's expected gain over imitation from entering a patent race. This equation is increasing in $w$ and $w^{*}$ for all $\mathbf{w} \in W$, because broadening patent protection in either country makes innovation more profitable and imitation less so.

\footnotetext{
${ }^{19}$ This can be thought of as reflecting randomness in the R\&D process that allows one of the firms to be slightly ahead in the process of innovation at the point where a significant resource commitment $(r)$ must be made.
} 
The payoffs in this model exhibit strategic substitutability with regard to the firm's choice of $R \& D$ action, since the expected profit from undertaking $R \& D$ is lower when the other firm is doing so as well. Specifically, we have $\psi\left(d, f^{*}, \mathbf{w} ; r\right)>\beta(\mathbf{w} ; r)$ for any given $r$ and $\mathbf{w} \in W$. Since $\beta(\mathbf{w} ; r)$ is increasing in $\mathbf{w}$, there will be a unique value of $r$ at which expected profits are zero when both firms engage in R\&D. We denote this value of $r$ by $\rho_{2}(\mathbf{w})$. If $r \leq \rho_{2}(0,0)$, a patent race arises even for the narrowest possible patent protection, while for $r>\rho_{2}\left(w_{\max }, w_{\max }\right)$ a patent race would never arise.

In this section we will limit attention to the parameter space where one firm will undertake $\mathrm{R} \& \mathrm{D}$ even with the narrowest patent protection $\mathbf{w}=(0,0)$, i.e. $\rho_{1}(0,0) \geq r$, and a patent race can be induced with sufficiently broad patent protection, i.e. $r>\rho_{2}(0,0)$. Government policy will then determine whether or not there is a patent race or whether only one firm will undertake R\&D. The following assumption restricts the parameter space of $r$ accordingly. ${ }^{20}$

A1. Assume $\rho_{1}(0,0)=\frac{2 \theta}{9} e^{2} \geq r>\rho_{2}(0,0)=\frac{2 \theta(1-\theta)}{9} e^{2}$.

The relationship between government policy and equilibrium industry structure is illustrated in Figure 3. The locus of values of $\mathbf{w}$ consistent with entry into R\&D by both firms, $\rho_{2}(\mathbf{w})=r^{0}$, is shown in Figure 3 for a particular value, $r=r^{0}$. Assumption A1 ensures that the $\rho_{2}(\mathbf{w})$ locus intersects $W$, as illustrated, but that the $\rho_{1}(\mathbf{w})$ locus does not. For $r=r^{0}$, both firms will have a patent race if $\mathbf{w}$ lies on or above the $\rho_{2}(\mathbf{w})=r^{0}$ locus. If $\mathbf{w}$ lies below the $\rho_{2}(\mathbf{w})=r^{0}$ locus then only one firm undertakes R\&D. This locus will be convex to the origin, and a value of $r$ greater than $r^{0}$ will be represented by a $\rho_{2}(\mathbf{w})$ locus to the right of $\rho_{2}(\mathbf{w})=r^{0}$.

For a given value of $w^{*}$, we can define $b\left(w^{*}, r\right)$ as the minimum home patent breadth required to induce a patent race. Figure 3 illustrates this for a particular value $w^{* 1}$ and corresponding $b\left(w^{* 1}, r\right)$. Note that since the $\rho_{2}(\mathbf{w})=r^{0}$ locus intersects the bottom horizontal axis, $b^{*}\left(w^{*}, r\right)$ will exist for all $w^{*}$. This arises because $\mathrm{R} \& \mathrm{D}$ costs are sufficiently low that the home government can induce a patent race even when the foreign country chooses the narrowest possible patent protection of 0 . However, this will not be the case if the $\rho_{2}(\mathbf{w})$ locus does not intersect the bottom horizontal axis, i.e. if $r>\rho_{2}\left(w_{\max }, 0\right)$. In that case $b\left(w^{*}, r\right)$ will only exist for $w^{*}$ sufficiently high. By symmetry of the model, the same logic applies for the foreign government.

\footnotetext{
${ }^{20}$ This restriction should be viewed as a restriction on the value of $r$ relative to $\theta$ rather than on $\theta$ itself. If $r>\rho_{1}(0,0)$ then governments could set patent breadths sufficiently narrow that no firm would undertake R\&D. If $r \leq \rho_{2}(0,0)$ then, as remarked above, a patent race could arise regardless of government policy choices. A1
} 


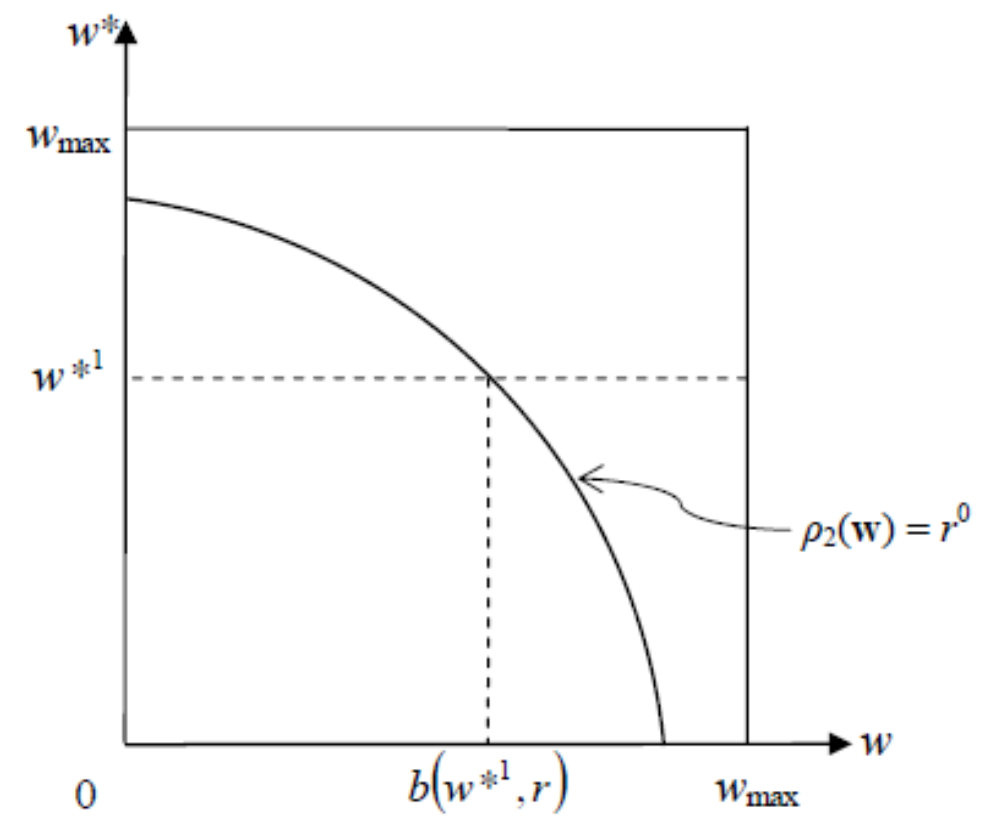

Figure 3: The Parameter Spaces for which R\&D by One or Both Firms is Profitable

We can now use the characterization of firm decisions at the second stage to solve for the best responses of the governments at the first stage. For the North-North model we will use the notation $\tilde{v}^{N N}\left(w, w^{*}\right)$ to denote home welfare. Since the North-North model is symmetrical, foreign welfare will be given by $\tilde{v}^{N N}\left(w^{*}, w\right)$ as well. ${ }^{21}$ Under our assumption that $\left\{d, f^{*}\right\}$ and $\left\{f, d^{*}\right\}$ occur with equal probability when $\mathrm{R} \& \mathrm{D}$ is profitable for only one firm, the payoff function of the home country is as follows: ${ }^{22}$

$$
\tilde{v}^{N N}(\mathbf{w} ; r)=\left\{\begin{array}{cc}
\theta(2-\theta) V(\mathbf{w})-r & \text { if } \beta(\mathbf{w} ; r) \geq 0 \\
\theta V(\mathbf{w})-r / 2 & \text { if } 0>\beta(\mathbf{w} ; r)
\end{array}\right.
$$

where $V(\mathbf{w})=\frac{1}{2} \Pi_{n}(\mathbf{w})+\frac{1}{2} \Pi_{m}(\mathbf{w})+S(\hat{Q}(w))$ is the sum of consumer and producer surplus in the event that an innovation is made. The home country expects a higher surplus from an innovation when both firms enter the patent race, but must pay a higher expected R\&D cost. The symmetry of the probability that either firm makes an innovation means that each country's

thus rules out ranges of the parameter space that are not particularly interesting from a policy perspective.

${ }^{21}$ We focus on a symmetrical model to show that an asymmetric equilibrium can arise in such an environment. This outcome would be less surprising in an asymmetrical environment, which would also be more cumbersome to work with. The results of our North-South model give a clear indication of the forces introduced by asymmetry and how the results are different.

${ }^{22}$ The reason that, in $\widetilde{v}^{N N}(\mathbf{w} ; r), r$ is divided by 2 if $0>\beta(\mathbf{w} ; r)$ is because under the strategy profile $\left\{d, f^{*}\right\}$ there is, ex ante, a probability of $1 / 2$ that the home firm is selected to choose first whether or not it wants to undertake R\&D. 
firm is equally likely to serve in the role of imitator and innovator, both in the outcome where one firm undertakes $\mathrm{R} \& \mathrm{D}$ and when both firms enter into a patent race. Differentiating $V(\mathbf{w})$ yields

$$
\frac{\partial V(\mathbf{w})}{\partial w}=-\hat{q}_{m}(w)<0 \quad \frac{\partial V(\mathbf{w})}{\partial w^{*}}=\frac{(5 w-e)}{9}
$$

Expected surplus is decreasing in the country's own patent breadth, $w$, because the expected loss in consumer surplus and imitator profits resulting from an increase in $w$ exceeds the expected gain in innovator profits. The fact that the home country's firm is equally likely to be innovator or imitator means that the national interest is aligned with the interests of consumers and the imitator. Note the contrast with the North-South model, where the fact that the home firm was always the innovator meant that national welfare was aligned with the interest of the innovator. The effect of the other country's patent breadth, $w^{*}$, operates through its impact on expected firm profits in the export market. Expected profits of the home firm are increasing (decreasing) in patent breadth for $w^{*}$ greater (less) than $e / 5$ by Lemma $2(a)$.

To derive the best-response function under A1, note that for given $w^{*}$ the home welfare expression (6) yields two different segments. If $b\left(w^{*}, r\right)$ exists, then only one firm engages in $\mathrm{R} \& \mathrm{D}$ for $w<b\left(w^{*}, r\right)$ and there is a patent race for $w \geq b\left(w^{*}, r\right)$. This case arises when $r$ is sufficiently low and/or $w^{*}$ is sufficiently high that Home can induce a patent race by making $w$ sufficiently high (e.g. $w^{* 1}$ in Figure 3). Home welfare $\tilde{v}^{N N}(\mathbf{w} ; r)$ has a discontinuity at the point $b\left(w^{*}, r\right)$ where the industry structure switches by the addition of a firm doing $\mathrm{R} \& \mathrm{D}$ as illustrated in Figure 4. Welfare is decreasing in $w$ on $\left[b\left(w^{*}, r\right), w_{\max }\right]$ from $(7)$, so the maximum on this interval occurs at $b\left(w^{*}, r\right)$. Similarly, welfare is decreasing in $w$ on $\left[0, b\left(w^{*}, r\right)\right)$, so the maximum on that interval occurs at 0 . Therefore, the home country will choose whichever of 0 or $b\left(w^{*}, r\right)$ yields a higher payoff. Figure 4 illustrates a case where $\tilde{v}^{N N}\left(0, w^{*} ; r\right) \geq \tilde{v}^{N N}\left(b\left(w^{*}, r\right), w^{*} ; r\right)$ but the reverse can also arise, for example if $r$ is relatively low. If $b\left(w^{*}, r\right)$ does not exist then only one firm engages in $\mathrm{R} \& \mathrm{D}$ for all $w \in\left[0, w_{\max }\right]$. In this case, since welfare is decreasing on $\left[0, w_{\max }\right]$, the best response is 0 .

This discussion shows that the home country's best response for patent breadth will be the minimum required to induce entry by the desired number of innovating firms. Since the home firm is equally likely to be innovator or imitator in the North-North model, the home government does not have the incentive to use patent breadth to shift profits to the innovating firm. Consumer interests dominate for a given number of firms engaged in $\mathrm{R} \& \mathrm{D}$, so the home 


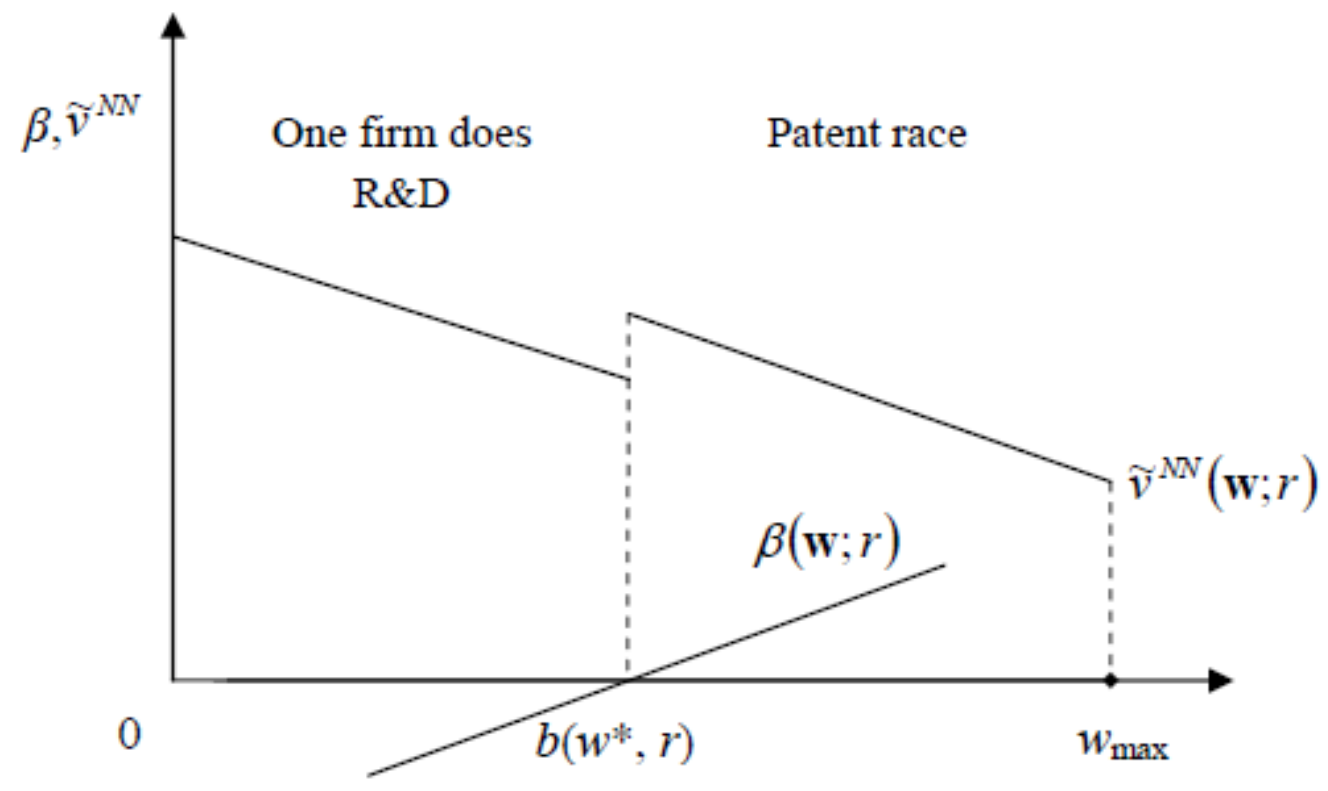

Figure 4: Home Welfare in the North-North Model (given foreign policy)

government does not want to allow any greater patent breadth than is necessary to induce the optimal number of firms to do R\&D. The foregoing discussion holds for the foreign country as well because its best-response function is symmetric to that of Home. These observations are summarized in the following result.

Lemma 4: Assume the North-North model. The home country's best-response function has the property that

a) If $b\left(w^{*}, r\right)$ exists, then the best response is $b\left(w^{*} ; r\right)$ if $\tilde{v}^{N N}\left(b\left(w^{*}, r\right), w^{*} ; r\right) \geq \tilde{v}^{N N}\left(0, w^{*} ; r\right)$ and 0 otherwise.

b) If $b\left(w^{*}, r\right)$ does not exist, then the best response is 0 .

We can use Lemma 4 to derive the necessary and sufficient conditions for $\hat{\mathbf{w}}=\left(\hat{w}, \hat{w}^{*}\right)$ to be part of a subgame perfect Nash equilibrium of the patent breadth game. 
Lemma 5: Assume the North-North model with $r \in\left[\rho_{2}(0,0), \rho_{1}(0,0)\right]$

(a) $\hat{\mathbf{w}}$ is an equilibrium with only one firm engaged in $R \& D$ iff $\hat{\mathbf{w}}=(0,0)$ and

$$
v^{N N}(0,0 ; r) \geq v^{N N}(w, 0 ; r) \text { for } w \in\left[0, w_{\max }\right]
$$

(b) $\hat{\mathbf{w}}$ is an equilibrium with a patent race iff $\rho_{2}(\hat{\mathbf{w}})=r$ and

$$
\begin{aligned}
& v^{N N}\left(\hat{\mathbf{w}} ; \rho_{2}(\hat{\mathbf{w}})\right) \geq v^{N N}\left(0, \hat{w}^{*} ; \rho_{2}(\hat{\mathbf{w}})\right) \\
& v^{N N}\left(\hat{\mathbf{w}} ; \rho_{2}(\hat{\mathbf{w}})\right) \geq v^{N N}\left(\hat{w}, 0 ; \rho_{2}(\hat{\mathbf{w}})\right)
\end{aligned}
$$

With only one firm undertaking R\&D, a country's payoff is maximized by choosing the narrowest patent protection. Therefore, any equilibrium where only one firm undertakes R\&D must have $\hat{\mathbf{w}}=(0,0)$. Part (a) shows that, in order for $\hat{\mathbf{w}}=(0,0)$ to be an equilibrium, it must dominate the payoff obtained by deviating to a patent breadth that would induce a patent race. If an equilibrium exists with a patent race, as in part (b), then it must involve choices of patent breadth such that firms are indifferent between engaging in $\mathrm{R} \& \mathrm{D}$ or not: $\rho_{2}(\hat{\mathbf{w}})=r$. Otherwise, national welfare could be increased by narrowing patent breadth in the country where the firm is not indifferent. Note that in the case of a patent race, the Nash equilibrium will not necessarily involve equal choices of patent breadth across countries.

\subsection{Symmetric Nash Equilibria}

We will focus initially on the existence of symmetric Nash equilibria. Figure 5 identifies the set of values of $(r, \theta)$ associated with A1. This parameter range lies between the $\rho_{2}(0,0)$ and $\rho_{1}(0,0)$ loci in Figure 5, where $\rho_{1}(0,0)$ is linear in $\theta$ and $\rho_{2}(0,0)=(1-\theta) \rho_{1}(0,0)$. We will identify the respective parameter ranges for which there is an equilibrium with a patent race, and an equilibrium with only a single firm undertaking $R \& D$. The reason for focusing on symmetric equilibria is to show the potential multiplicity of equilibria and how international agreements to coordinate policy could raise welfare without requiring transfers.

We first identify the parameter range for which $(0,0)$ is an equilibrium. By Lemma 5(a), it will fail to be an equilibrium if one government can choose $b\left(w^{*}, r\right)$ such that entry into a patent race by the second firm will be induced and the government will obtain a higher payoff from this. The $h(\theta)$ locus is defined as the locus of $(r, \theta)$ combinations for which $\tilde{v}^{N N}\left(0,0 ; \rho_{2}(w, 0)\right)=$ $\tilde{v}^{N N}\left(w, 0 ; \rho_{2}(w, 0)\right)$; that is, given that the foreign government sets $w^{*}=0$, along the $h(\theta)$ locus 


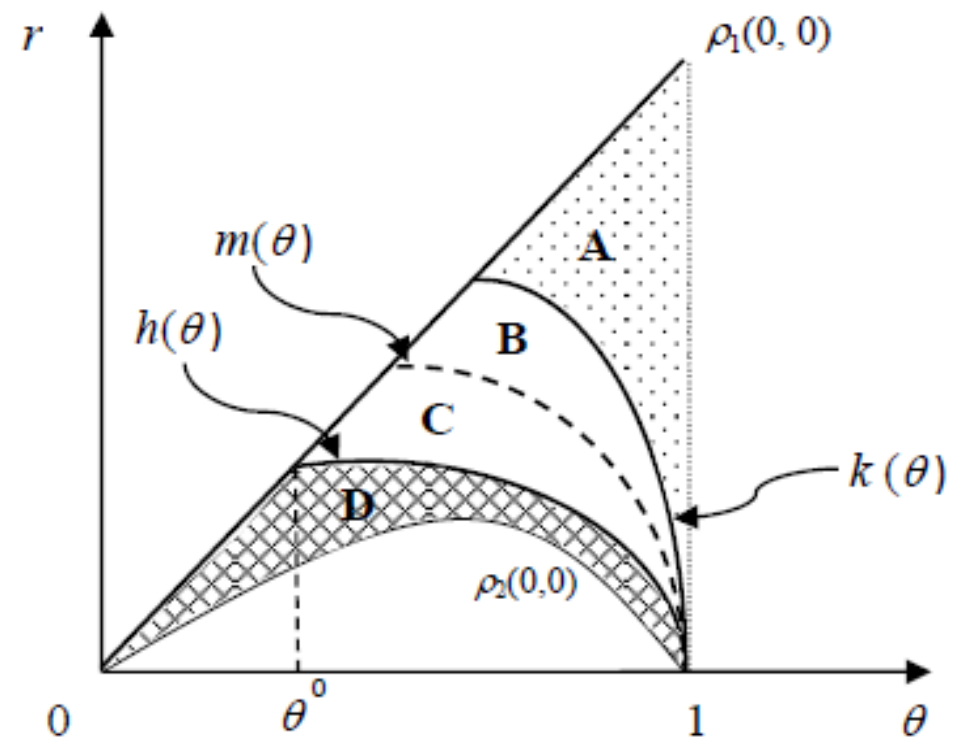

Figure 5: Characterization of Equilibria under A1

the home government is just indifferent between setting $w=0$, inducing only one firm to undertake $\mathrm{R} \& \mathrm{D}$, and setting $w>0$ at the level that is just sufficient to induce a patent race between both firms. It is shown in the Appendix that the $h(\theta)$ locus must be negatively sloped and will intersect the $\rho_{1}(0,0)$ locus at $\theta_{0} \approx .476$ as illustrated in Figure 5 . The pair $(0,0)$ cannot be an equilibrium for $\theta<\theta_{0}$ because the probability of success by one firm is sufficiently low that one government will find it optimal to offer patent protection sufficiently broad to induce both firms to engage in $\mathrm{R} \& \mathrm{D}$. Note also that $\tilde{v}^{N N}\left(0,0 ; \rho_{2}(w, 0)\right)-\tilde{v}^{N N}\left(w, 0 ; \rho_{2}(w, 0)\right)$ is increasing in $r$, so $(0,0)$ is an equilibrium in the regions $\mathbf{A}, \mathbf{B}$ and $\mathbf{C}$ above the $h(\theta)$ locus in Figure 5 . A higher value of $r$ raises the fixed cost of $R \& D$, which makes the industry equilibrium in which only one firm undertakes R\&D relatively more attractive. Using a similar argument, $(0,0)$ fails to be an equilibrium in region $\mathbf{D}$, below the $h(\theta)$ locus, because at such relatively low values of $r$ a patent race can be induced with a relatively narrow patent breadth.

We next consider the conditions under which there can be a symmetric equilibrium with a patent race. A symmetric equilibrium is one in which each country chooses the same patent breadth, $(\hat{w}, \hat{w})$ where $\hat{w}=b(\hat{w} ; r)$. This symmetric pair will be an equilibrium if it yields higher welfare to the home country than could be obtained from a deviation by the home government to $w=0$. This deviation involves a trade-off of the loss from the lower probability of successful innovation when only one firm undertakes $R \& D$ against the gain from shifting the cost of patent 
protection onto foreign consumers. The choice of $w=0$ becomes more attractive relative to the symmetric patent race equilibrium as $r$ increases, because a higher value of $r$ lowers the payoff in the patent race by more than it lowers the payoff when only one firm engages in R\&D. It is shown in the Appendix that for values of $\theta$ sufficiently low, entry into $R \& D$ by a second firm is sufficiently profitable that there will be a symmetric patent race equilibrium for all $r \in\left[\rho_{2}(0,0), \rho_{1}(0,0)\right]$. For larger values of $\theta$, there will be a threshold value $k(\theta)$ such that the patent race equilibrium does not exist for $r>k(\theta)$. The $k(\theta)$ locus is also illustrated in Figure 5. For values below (above) the $k(\theta)$ locus a patent race with $w=b(w ; r)$ is (is not) an equilibrium in the patent breadth game. Therefore, symmetric equilibria $\hat{\mathbf{w}}=(\hat{w}, b(\hat{w} ; r))$ exist for values of $(r, \theta)$ in regions $\mathbf{B}, \mathbf{C}$ and $\mathbf{D}$ of Figure 5 . This establishes that a symmetric Nash equilibrium exists for all $(r, \theta)$ in these regions. We can summarize this discussion as follows.

Proposition 3. Assume the North-North model and that A1 holds. There exist values $h(\theta), k(\theta) \in\left(\rho_{2}(0,0), \rho_{1}(0,0)\right]$ with $k(\theta) \geq h(\theta)$ such that:

(a) For $r \in\left[h(\theta), \rho_{1}(0,0)\right]$ there exists a Nash equilibrium with $\hat{\mathbf{w}}=(0,0)$ wherein one firm undertakes $R \& D$.

(b) For $r \in\left[\rho_{2}(0,0), k(\theta)\right]$ there exists a symmetric Nash equilibrium with a patent race and patent breadth $w=b(w ; r)$ in each country.

The proof is in the Appendix. Proposition 3 illustrates that the equilibria with a patent race are sustainable in regions where $r$ and $\theta$ are relatively low. Lower values of both of these parameters make $R \& D$ by a second firm more attractive, and thus make an equilibrium with a patent race more likely.

Proposition 3 also establishes that for $r \in[h(\theta), k(\theta)]$, which corresponds to regions $\mathbf{B}$ and $\mathbf{C}$ of Figure 5, there will be two symmetric Nash equilibria. One is an equilibrium with $\hat{\mathbf{w}}=(0,0)$ and only one firm undertaking $\mathrm{R} \& \mathrm{D}$, and the other is an equilibrium with broader patent protection $\hat{\mathbf{w}}=(\hat{w}, b(\hat{w} ; r))$ and a patent race. The potential for equilibria involving multiple industry structures suggests a coordination failure on the part of the governments. A government does not find it profitable to broaden protection to induce entry into $R \& D$ when the other government chooses the narrowest patent protection. But it does find it desirable to induce entry into $\mathrm{R} \& \mathrm{D}$ with broader protection if the other government also provides broader protection. 
The existence of multiple symmetric equilibria raises the question of whether the equilibrium with only one firm undertaking $R \& D$ provides lower or higher welfare than the equilibrium with a patent race. The $m(\theta)$ locus in Figure 5 shows the $(r, \theta)$ combinations for which the Nash equilibrium $(0,0)$, where only one firm engages in $R \& D$, yields the same level of national welfare as the Nash equilibrium with $\hat{w}=b(\hat{w} ; r)>0$ and a patent race. For equilibria below the $m(\theta)$ locus and above the $h(\theta)$ locus, the patent race equilibrium yields higher world welfare. For equilibria above the $m(\theta)$ locus and below the $k(\theta)$ locus, it is the equilibrium where one firm undertakes R\&D that yields higher world welfare. This set of outcomes is summarized in the following result, with a proof being given in the Appendix.

Proposition 4. Assume the North-North model and $r \in\left(\rho_{2}(0,0), \rho_{1}(0,0)\right]$. There exists a value $m(\theta)$, satisfying $h(\theta) \leq m(\theta) \leq k(\theta)$, such that

(a) For $r \in[h(\theta), m(\theta))$, the symmetric patent race equilibrium yields higher welfare than can be obtained with only one firm undertaking $R \& D$.

(b) For $r \in(m(\theta), k(\theta)]$, the equilibrium with only one firm undertaking $R \& D$ yields higher welfare than the symmetric patent race equilibrium.

In the regions $\mathbf{B}$ and $\mathbf{C}$, if the countries are in the symmetric Nash equilibrium that yields lower world welfare, there is the potential for a cooperative agreement to improve welfare without transfers between countries. An international agreement would allow countries to coordinate patent breadth on the higher payoff equilibrium. This coordination would involve both governments raising patent breadth if there is an equilibrium with only one firm in region $\mathbf{C}$ or, more surprisingly, reducing patent breadth if there is a patent race equilibrium in region $\mathbf{B}$.

\subsection{Asymmetric Nash Equilibria}

In addition to the symmetric equilibria there exist asymmetric Nash equilibria with a patent race. Since, by Lemma $4 \mathrm{a}$, the home best response in a patent race equilibrium is $b\left(w^{*}, r\right)$, the asymmetric equilibria will all take the form $\left(b\left(w^{*}, r\right), w^{*}\right)$. As in the symmetric patent race equilibria, countries provide the minimum patent protection to induce a patent race in equilibrium. The only difference is that in the asymmetric equilibria the country with the broader patent protection will bear a higher share of the cost in terms of lost consumer surplus. 
Proposition 5. Assume the North-North model and $r \in\left(\rho_{2}(0,0), \rho_{1}(0,0)\right]$.

(a) The pair $(b(0, r), 0)$ is an equilibrium with a patent race for $r \leq \min \left[\rho_{1}(0,0), h(\theta)\right]$.

(b) For $r \in\left[\rho_{2}(0,0), k(\theta)\right)$, there exist asymmetric patent race equilibria with patent breadths in the neighborhood of the symmetric equilibrium.

In the Appendix, the proof of Proposition 5 establishes that $(0,0)$ is not an equilibrium in region $\mathbf{D}$ of Figure 5 . In this region, there would be an incentive to deviate to $(b(0, r), 0)$ which is an equilibrium with a patent race. However, $(b(0, r), 0)$ is not an equilibrium outside of region D. Since deviation incentives will be larger for the country with the broader patent protection, asymmetric equilibria will be more difficult to support in general. Part (b) establishes that, in the interior of regions $\mathbf{B}$ and $\mathbf{C}$ of Figure 5, patent breadths can be different but must be sufficiently close to each other in order to be sustainable as asymmetric equilibria.

\section{Conclusions}

We considered two versions of our model: a North-South model in which the Southern firm can imitate but not innovate and a North-North model in which firms in each country have the same probability of success at making an innovation. In the North-South model, countries use patent breadth for profit-shifting reasons. The North chooses the broadest patent protection to protect from Southern imitation, while the Southern government chooses the narrowest patent protection consistent with innovative activity by the Northern firm. The Southern government chooses narrow patent protection to benefit Southern consumers and the imitating firm. This results in a unique Nash equilibrium for patent breadth. We showed that the level of patent protection in the Nash equilibrium could be either higher or lower than the socially optimal level. However, there was no scope for agreement over patent breadths in the absence of lump sum transfers in the North-South model. This occurs because of the asymmetry of interests between North and South: The North wants broad patent breadth to generate profits for its innovating firm while the South wants narrow patent breadth for its consumers and imitating firm.

In the North-North model, by contrast, the interests of the two countries are symmetric because the firm in each has an equal chance of being the innovator. In this case there is a free- 
rider problem that can lead to a multiplicity of equilibria for a given industry structure. Each country would prefer that the other pay for R\&D by imposing broad patent protection, so each will choose the minimum protection required to induce the desired number of firms to undertake R\&D, given the other country's policy. The North-North model also has the feature that both a patent race and $R \& D$ by only one firm may arise in a Nash equilibrium in patent breadth for some parameter values. In this case, an agreement to coordinate levels of patent breadth could be welfare improving in the North-North model in the absence of transfers. The cooperative agreement in the North-North model could involve either an increase or, more surprisingly, a decrease over the levels set non-cooperatively by national governments. This could explain why coordination over patent breadth at the European Union level, through the EPO, could improve welfare; either by granting patents where individual member governments had failed to do so or alternatively by revoking patents where they had been granted by individual member governments.

A promising direction for future work would be, following Bessen and Maskin (2009), to consider the possibility that imitation is a productive activity for the imitating firm and thus raise the likelihood of future innovation by that firm. Bessen and Maskin (2009) show that an equilibrium with patent protection might yield lower social welfare than an equilibrium without patent protection when the act of imitation produces knowledge that may affect the future rate of innovation. They analyze this in a model of sequential innovation where firms produce differentiated products, which results in a complementarity in innovative activity between firms. However, their setting is domestic and does not allow for strategic interaction in the breadth of patent setting across countries. In a model that combined the Bessen-Maskin framework with ours, very broad patent protection in the North could have the adverse effect of reducing the degree of accumulation of knowledge for future innovation. This effect could add to the benefit that we have demonstrated of an agreement to lower patent breadth. 


\section{A Appendix}

Proof of Lemma 2. From Lemma 1, industry profit gross of R\&D costs is $\pi_{m}(w)+\pi_{n}(w)=$ $\left(2 e^{2}-2 e w+5 w^{2}\right) / 9$ and consumer surplus is $S(\hat{Q}(w))=(2 e-w)^{2} / 18$. Lemma 2 follows by differentiation of these functions.

\section{Extension to General Utility Function.}

We can also show that the basic properties of the surplus function illustrated in Figure 1 hold for more general utility functions. This is demonstrated in the following Lemma.

Lemma A.1. Let the utility function have the form $U\left(q_{m}, q_{n}\right)=u\left(q_{m}+q_{n}\right)-w q_{m}$, where $u$ is a strictly concave function on $[0, \bar{Q}]$. Under the standard Cournot-Nash stability condition, total surplus $\sigma(w)=S(\hat{Q}(w))+\hat{\pi}_{n}(w)+\hat{\pi}_{m}(w)$ will satisfy $\sigma^{\prime}(0)<0$ and $\sigma(0)>\sigma\left(w_{\max }\right)$. It will also satisfy $\sigma^{\prime}\left(w_{\max }\right)>0$ if $q_{n}$ and $q_{m}$ are strategic substitutes.

We begin by deriving the relationship between patent breadth and the outputs of the innovator and the imitator. Letting $p(Q)=u^{\prime}(Q)$ denote the inverse demand function, the necessary conditions for profit maximization of the respective firms are:

$$
\begin{aligned}
p(Q)+q_{n} p^{\prime}(Q) & =0 \\
p_{n}(Q)-w+q_{m} p^{\prime}(Q) & =0
\end{aligned}
$$

where we are using the fact that $p_{n}=p(Q)$ and $p_{m}=p(Q)-w$. Differentiating these first order conditions and solving yields the comparative statics results

$$
\frac{d q_{n}}{d w}=\frac{-\left(p^{\prime}(Q)+q_{n} p^{\prime \prime}(Q)\right)}{\Delta} \text { and } \frac{d q_{m}}{d w}=\frac{2 p^{\prime}(Q)+q_{n} p^{\prime \prime}(Q)}{\Delta},
$$

where $\Delta \equiv p^{\prime}(Q)\left(3 p^{\prime}(Q)+Q p^{\prime \prime}(Q)\right)$. We impose the standard Cournot-Nash stability condition that $\Delta>0$, which ensures that $\frac{d q_{m}}{d w}<0$. Note however that the general case allows for the possibility that $\frac{d q_{n}}{d w}<0$ if the inverse demand function is sufficiently convex. Combining these results yields the conclusion that total output must be decreasing in $w$,

$$
\frac{d Q}{d w}=\frac{d q_{n}}{d w}+\frac{d q_{m}}{d w}=\frac{p_{n}^{\prime}(Q)}{\Delta}<0 .
$$

Letting $\hat{\pi}_{i}(w)$ denote the equilibrium profit of a firm of type $i$, we have by the envelope theorem that $\frac{d \hat{\pi}_{i}(w)}{d w}=q_{i} p^{\prime}(Q(w)) \frac{d q_{j}}{d w}$ for $i, j=m, n$ and $i \neq j$. 
Consumer surplus can be expressed as $S(\hat{Q}(w))=U(\hat{Q}(w))-p(\hat{Q}(w)) \hat{Q}(w)$. An increase in $w$ must increase consumer surplus, since $\frac{d S}{d w}=-p^{\prime}(\hat{Q}(w)) \hat{Q}(w) \frac{d Q}{d w}>0$. Combining this with the effect on profits, we obtain

$$
\sigma^{\prime}(w)=-q_{n} p^{\prime}(Q) \frac{d q_{n}}{d w}-q_{m} p^{\prime}(Q) \frac{d q_{m}}{d w} .
$$

At $w=w_{\max }$ we have $q_{m}=0$, so $(10)$ becomes $\sigma^{\prime}(w)=-p_{n}^{\prime}(Q) q_{n} \frac{d q_{n}}{d w}$. Thus, total surplus is increasing at $w=w_{\max }$ if $d q_{n} / d w>0$. Since $q_{m}$ is decreasing in $w$, we require only that $q_{m}$ and $q_{n}$ be strategic substitutes in order for $d q_{n} / d w>0$.

At $w=0$, we have that $q_{m}=q_{n}$ and $(10)$ becomes $\sigma^{\prime}(w)=-p^{\prime}(Q) q_{n} \frac{d Q}{d w}<0$. Finally, we must have that total surplus is greater at $w=0$ than at $w=w_{\max }$ because the latter is the monopoly solution at which only one firm produces positive output.||

\section{Proof of Proposition 2:}

World welfare is maximized by choosing $\mathbf{w}$ to maximize $\Omega(\mathbf{w} ; r)$ subject to the non-negativeexpected-profit constraint $\psi(d, f, \mathbf{w} ; r) \geq 0$. Since $\Omega(a, b ; r)=\Omega(b, a ; r)$, we restrict attention to solutions where $w \geq w^{*}$. We first show that if the constraint is binding, i.e. $\psi(d, f, \mathbf{w} ; r)=0$, then world welfare is maximized by choosing the maximum home patent breadth consistent with $\psi(d, f, \mathbf{w} ; r)=0$. Begin by assuming $\psi(d, f, \mathbf{w} ; r)=0$. Now consider the effect of an increase in $w^{*}$ accompanied by a reduction in $w$ to maintain $\psi\left(d, f^{*}, w, w^{*} ; r\right)=0$, which requires $d w / d w^{*}=-\left(e+w^{*}\right) /(e+w)$. Using (4) and (5), the effect of this change on world welfare is

$$
\frac{d\left(\tilde{v}+\tilde{v}^{*}\right)}{d w^{*}}=\frac{5 \theta e\left(w^{*}-w\right)}{3(e+w)}
$$

An increase in $w^{*}$ will reduce world welfare if $w^{*}<w$. This means that world welfare is maximized by choosing the maximum home patent breadth $w$ consistent with $\psi(d, f, \mathbf{w} ; r)=0$.

To find the world welfare optimum, with a view to proving parts (a)-(c), we compare welfare at points where the zero-expected-profit constraint is slack with welfare at the best point where the constraint binds. If $r \in\left(\rho_{1}\left(w_{\max }, 0\right), \rho_{1}\left(w_{\max }, w_{\max }\right)\right)$, the highest welfare with a binding zero-expected-profit constraint occurs on the right hand boundary of $W$ in Figure 2, with $\mathbf{w}=\left\{w_{\max }, j\left(w_{\max }, r\right)\right\}$. This pair is also the Nash equilibrium by Proposition 1. By Lemma $2 \mathrm{~b}$, the pair $\left\{w_{\max }, w_{\max }\right\}$ sustains $\mathrm{R} \& \mathrm{D}$ and yields higher welfare than $\left\{w_{\max }, j\left(w_{\max }, r\right)\right\}$ for $j\left(w_{\max }, r\right)>\frac{5 e}{22}$. Since this yields the highest payoff consistent with $\psi(d, f, \mathbf{w} ; r) \geq 0$ in this interval, world welfare is maximized at $\left\{w_{\max }, w_{\max }\right\}$. For $r \in\left(\rho_{1}\left(w_{\max }, \frac{5 e}{22}\right), \rho_{1}\left(w_{\max }, w_{\max }\right)\right)$, 
under the world welfare maximum patent breadth in the foreign country exceeds that in the Nash equilibrium. This establishes part (a).

For $r \in\left[\rho_{1}\left(w_{\max }, 0\right), \rho_{1}\left(w_{\max }, \frac{5 e}{22}\right)\right]$, welfare at $\left\{w_{\max }, j\left(w_{\max }, r\right)\right\}$ exceeds that at $\left\{w_{\max }, w_{\max }\right\}$ by Lemma $2 \mathrm{~b}$, so the Nash equilibrium pair $\left\{w_{\max }, j\left(w_{\max }, r\right)\right\}$ maximizes world welfare. For $r<\rho_{1}\left(w_{\max }, 0\right)$, the highest welfare with a binding zero-expected-profit constraint occurs on the lower boundary of $W$ with $\mathbf{w}=\{j(0, r), 0\}$. The argument here is similar to that on the right boundary. If $j(0, r)>\frac{5 e}{22}$, then $\left\{w_{\max }, 0\right\}$ sustains $\mathrm{R} \& \mathrm{D}$ and yields higher welfare than $\{j(0, r), 0\}$ and yields non-negative expected profit. It also yields higher welfare than $\left\{w_{\max }, w_{\max }\right\}$, so the Nash equilibrium value of $\left\{w_{\max }, 0\right\}$ is socially optimal for $r \in\left[\rho_{1}\left(\frac{5 e}{22}, 0\right), \rho_{1}\left(w_{\max }, 0\right)\right)$. Combining this with the discussion for $r \in\left[\rho_{1}\left(w_{\max }, 0\right), \rho_{1}\left(w_{\max }, \frac{5 e}{22}\right)\right]$ establishes part (b).

Finally, for $r<\left(\rho_{1}\left(\frac{5 e}{22}, 0\right)\right.$ the pair $\{j(0, r), 0\}$ that yields zero expected profit will yield higher welfare than the pair $\left\{w_{\max }, 0\right\}$. Therefore, the world welfare maximizing patent breadth of $\{j(0, r), 0\}$ for the home government is less than that in the Nash equilibrium when $r<$ $\left(\rho_{1}\left(\frac{5 e}{22}, 0\right)\right.$, which proves $(\mathrm{c}) \cdot \|$

\section{Proof of Proposition 3:}

a) Lemma 5 established that (8) must be satisfied in order for $\hat{\mathbf{w}}=(0,0)$ to be a Nash equilibrium. A sufficient condition for (8) to be satisfied is that $r \geq \rho_{2}\left(w_{\max }, 0\right)$, because $r$ is sufficiently high that the home country is unable to induce a patent race by increasing $w$. In this case, $\frac{\partial v^{N N}}{\partial w}=\theta \frac{\partial V}{\partial w}<0$ for $w \in\left[0, w_{\max }\right]$ so Home's best response is $w=0$. The set of values satisfying this condition is given by $r \in\left[\rho_{2}\left(w_{\max }, 0\right), \rho_{1}(0,0)\right]=\left[\theta e^{2}(26-17 \theta) / 72\right.$, $\left.2 \theta e^{2} / 9\right]$. The function $g(\theta)=\rho_{2}\left(w_{\max }, 0\right)$ for $\rho_{2}\left(w_{\max }, 0\right) \leq \rho_{1}(0,0)$. Since $\rho_{2}\left(w_{\max }, 0\right)=\rho_{1}(0,0)$ is solved by $\theta=10 / 17$, the region $r \in\left[g(\theta), \rho_{1}(0,0)\right]$ is non-empty for $\theta \geq 10 / 17$. Because the foreign government's payoffs are symmetrical, its best response is $w^{*}=0$ over this range as well. Therefore, the unique Nash equilibrium over this range is $\hat{\mathbf{w}}=(0,0)$.

For $r \in\left(\rho_{2}(0,0), \rho_{2}\left(w_{\max }, 0\right)\right]$, the home country can induce a patent race but it can also induce only one firm to undertake R\&D. Defining $\tilde{v}^{N N}(w, 0 ; r)-\tilde{v}^{N N}(0,0 ; r)$ to be the home country's gain from broadening its patent breadth to induce a patent race, it follows from (8) that $(0,0)$ will be an equilibrium if $\tilde{v}^{N N}(w, 0 ; r)-\tilde{v}^{N N}(0,0 ; r) \leq 0$. We will now establish the lower boundary of $(r, \theta)$ combinations for which $\hat{\mathbf{w}}=(0,0)$, referred to as $h(\theta)$. Along $h(\theta)$, each government is indifferent between inducing a patent race and inducing one firm to undertake 
R\&D. First define the function

$$
\tilde{H}(w, \theta) \equiv \tilde{v}^{N N}(w, 0 ; \rho(w, 0))-\tilde{v}^{N N}(0,0 ; \rho(w, 0))
$$

where use of $r=\rho(w, 0)$ ensures the profitability of a patent race. We use the intermediate value theorem to show that for $\theta \in\left[\frac{2}{5}, 1\right]$ there will exist a $w \in\left[0, w_{\max }\right]$ that satisfies $\tilde{H}(w, \theta)=$ 0 . The function $\tilde{H}(w, \theta)$ has the properties that it is positive at $w=0$ and monotonically decreasing over the range $w \in\left[0, w_{\max }\right]$. To see this, observe that $\tilde{H}(0, \theta)=\frac{\theta e^{2}}{3}(1-\theta)>0$ for $\theta \in(0,1)$ and $\partial \tilde{H}(w, \theta) /\left.\partial w\right|_{w=0}=-\frac{\theta e}{18}(14-5 \theta)<0, \partial \tilde{H}(w, \theta) /\left.\partial w\right|_{w=w_{\max }}=-\frac{\theta e}{12}(2-\theta)<0$, where $\partial^{2} \tilde{H}(w, \theta) / \partial w^{2}=\frac{\theta}{18}(22-7 \theta)$ establishes monotonicity. Now observe that $\tilde{H}\left(w_{\max }, \theta\right)=$ $\frac{7 \theta e^{2}}{144}(2-5 \theta)$ which is negative for $\theta \in\left[\frac{2}{5}, 1\right)$. So by the intermediate value theorem there must exist a value of $w$ at which $\tilde{H}(w, \theta)=0$. We denote this value by $\omega(\theta)$, which is given by

$$
\omega(\theta)=e\left(\frac{14-5 \theta-\sqrt{208 \theta-59 \theta^{2}-68}}{22-7 \theta}\right)
$$

Note that $\omega(\theta)>0$ for all $\theta \in(0,1)$. The lower boundary for which $\hat{\mathbf{w}}=(0,0)$ is then given by substituting $\omega(\theta)$ for $w$ in $\rho_{2}(w, 0)$. Since $\rho_{1}(0,0)$ is increasing in $\theta$ and $\rho_{2}(\omega(\theta), 0)$ is decreasing in $\theta$, there is a unique value $\theta_{0} \approx .476$ such that $\rho_{2}(\omega(\theta), 0) \leq \rho_{1}(0,0)$ iff $\theta \geq \theta_{0}$. Note that $\theta_{0}>\frac{2}{5}$. This establishes that the lower boundary of $(r, \theta)$ combinations for which $\hat{\mathbf{w}}=(0,0)$ is the function $\rho_{2}(\omega(\theta), 0)$ for $\theta \in\left(\theta_{0}, 1\right)$, so $h(\theta)=\rho_{2}(\omega(\theta), 0)$ for $\theta \in\left(\theta_{0}, 1\right)$. The fact that

$$
\partial\left(\tilde{v}^{N N}(w, 0 ; r)-\tilde{v}^{N N}(0,0 ; r)\right) / \partial r=-\frac{1}{2}
$$

confirms that $\tilde{v}^{N N}(w, 0 ; r)-\tilde{v}^{N N}(0,0 ; r)<0$ for all $r \in\left(\rho_{2}(\omega(\theta), 0), \min \left(\rho_{1}(0,0), \rho_{2}\left(w_{\max }, 0\right)\right)\right]$, as required for $\hat{\mathbf{w}}=(0,0)$ to be an equilibrium throughout the relevant range.

b) We begin by defining a function that can be used to characterize all pairs $\hat{\mathbf{w}}$ that satisfy the conditions for a Nash equilibrium with a patent race as defined in Lemma 5b. Let

$$
Z(x, y) \equiv \tilde{v}^{N N}\left(x, y ; \rho_{2}(x, y)\right)-\tilde{v}^{N N}\left(0, y ; \rho_{2}(x, y)\right)
$$

which is the difference between the payoff to the home country when firms are indifferent between engaging and not engaging in $\mathrm{R} \& \mathrm{D}$ with patent breadths $(x, y)$ and the home country's payoff if it deviates to $(0, y)$. By Lemma $5 \mathrm{~b}$, any Nash equilibrium with a patent race must involve zero expected gain from engaging in R\&D. A pair $(x, y)$ with a zero expected gain patent race is a Nash equilibrium if $Z(x, y) \geq 0$ and $Z(y, x) \geq 0$. Therefore, a pair of symmetric patent breadths $(w, w)$ is an equilibrium for $r=\rho(w, w)$ if $Z(w, w) \geq 0$. 
Define $K(w)=Z(w, w)$. Identifying the set of symmetric Nash equilibria is equivalent to finding the values of $w$ for which $K(w) \geq 0$. Differentiating $K(w)$ yields the fact that $K$ is strictly convex in $w$ for $\theta \in[0,1]$, with

$$
\frac{d K(w)}{d w}=\frac{w(5-2 \theta)-e(3-\theta)}{3} .
$$

Since $\frac{d K\left(w_{\max }\right)}{d w}=-e \theta / 6<0, K(w)$ is decreasing in $w$ on $\left[0, w_{\max }\right]$. Note also that $K(0)=$ $H(0)>0$, so $(w, w)$ must be an equilibrium for $w$ sufficiently small. This yields two possibilities. If $K(w)$ is non-negative for all $w$ such that $\rho_{2}(w, w)<\rho_{1}(0,0)$, then $(w, w)$ is always an equilibrium. If there exists $w$ such that $\rho_{2}(w, w)<\rho_{1}(0,0)$ and $K(w)=0$, then $(w, w)$ fails to be an equilibrium for all higher values of $w$. Solving $K(w)=0$ yields the critical value for $w$ to be

$$
\gamma(\theta)=e\left(\frac{3-\theta-\sqrt{8 \theta-3 \theta^{2}-1}}{5-2 \theta}\right) .
$$

Setting $k(\theta)=\min \left[\rho_{2}(\gamma(\theta), \gamma(\theta)), \rho_{1}(0,0)\right]$, a symmetric patent race equilibrium will exist for $r \in \min \left(\rho_{2}(0,0), k(\theta)\right]$. Note that $\rho_{2}(\gamma(\theta), \gamma(\theta))<\rho_{1}(0,0)$ for $\theta \geq \theta_{2} \approx .55$. This yields the desired cutoff.

Proof of Proposition 4: Let $M(w, \theta)=\tilde{v}^{N N}\left(w, w ; \rho_{2}(w, w)\right)-\tilde{v}^{N N}\left(0,0 ; \rho_{2}(w, w)\right)$ be the difference in payoff between a patent race equilibrium with breadth $w$ and the payoff with only one firm engaging in $R \& D$. We can limit attention to $\theta \geq .476$, since for lower values of $\theta$ no equilibrium will exist with only one firm engaged in R\&D. $M$ is strictly convex in $w$ with $\partial M\left(w_{\max }, \theta\right) / \partial w=0$, so $M(w, \theta)$ is decreasing in $w$ on $\left[0, w_{\max }\right]$. Solving for the value of $w$ at which $M(w, \theta)=0$ yields

$$
\mu(\theta)=e\left(\frac{10-3 \theta-\sqrt{96 \theta-20-27 \theta^{2}}}{20-6 \theta}\right) .
$$

This solution satisfies $\mu(\theta) \in\left[0, w_{\max }\right]$ for $\theta \geq 2 / 9$, which holds over the interval of interest. Let $m(\theta)=\rho_{2}(\mu(\theta), \mu(\theta))$, where $m(\theta) \leq \rho_{1}(0,0)$ for $\theta_{1} \approx .527$. Since $\mu(\theta) \leq \gamma(\theta)$ over the relevant range, $m(\theta) \leq k(\theta)$. It can be shown that $m(\theta) \geq h(\theta)$ as well. Therefore, the patent race equilibrium is preferred for $r \in\left[h(\theta), \min \left(\rho_{1}(0,0), m(\theta)\right)\right)$ and the equilibrium with one firm undertaking $\mathrm{R} \& \mathrm{D}$ is preferred for $r \in\left(m(\theta), \min \left(\rho_{1}(0,0), k(\theta)\right] . \|\right.$

Proof of Proposition 5: (a) Follows immediately from Lemma 5b and Proposition 3a. 
b) $Z(x, y)$ is strictly convex in $(x, y)$ with $Z_{x x}=\frac{(22-7 \theta) \theta}{18}>0, Z_{y y}=\frac{(8-5 \theta) \theta}{18}>0$, and $Z_{x y}=$ 0 . Furthermore, $x>y$ implies $Z(x, y)-Z(y, x)=-\frac{1}{18}(x-y)[e(10-4 \theta)-(x+y)(7-\theta)]<0$ for $x, y \in\left[0, w_{\max }\right]$ and $\theta \in(0,1)$. Thus, the government who sets broader patent protection will have a larger incentive to deviate from a zero-expected-profit patent race when patent breadths are asymmetric. We know from Proposition $3 \mathrm{~b}$ that there exists a $w_{0}$ such that $Z\left(w_{0}, w_{0}\right)>0$ in this region. By the continuity of $Z$ and $\rho_{2}$, there will exist some $\varepsilon^{+}>0>\varepsilon^{-}$such that $\rho_{2}\left(w_{0}+\varepsilon^{+}, w_{0}+\varepsilon^{-}\right)=\rho_{2}\left(w_{0}, w_{0}\right), Z\left(w_{0}+\varepsilon^{+}, w_{0}+\varepsilon^{-}\right)>0$ and $Z\left(w_{0}+\varepsilon^{-}, w_{0}+\varepsilon^{+}\right)>0$. Thus, $\left(w_{0}+\varepsilon^{+}, w_{0}+\varepsilon^{-}\right)$and $\left(w_{0}+\varepsilon^{-}, w_{0}+\varepsilon^{+}\right)$will also be equilibria. Note however that this result cannot be established for $Z(w, w)=0$ because there exist no local changes satisfying $d \rho_{2}=0$ such that both governments prefer the agreement to choosing the minimum patent breadth.|| 


\section{References}

[1] Bessen, James, and Eric Maskin, (2009); "Sequential Innovation, Patents, and Imitation." RAND Journal of Economics, 40(4): 611-635.

[2] Bond, Eric W. and Kamal Saggi (2014), "Compulsory Licensing, Price Controls, and Access to Foreign Patented Products," Journal of Development Economics, 109, 217-228.

[3] Bonitatibus, K.M., (2001-02); "The Community Patent System Proposal and Patent Infringement Proceedings: An Eye Towards Greater Harmonization in European Intellectual Property Law." Pace Law Review, 22: 201-237.

[4] Chor, Davin, and Edwin Lai (2014); "Cumulative Innovation, Growth and the Protection of Ideas." CESifo Working Paper no. 4407.

[5] Chu, Angus and Shin-Kun Peng (2010), "International Intellectual Property Rights: Effects on Growth, Welfare, and Income Inequality, Journal of Macroeconomics, 33 (2), 276-287.

[6] Crawford, P., M. Feely, A. Guberman and G. Kramer (2006); "Are there potential problems with generic substitution of antiepileptic drugs? A review of issues." Seizure, 15:165-176.

[7] Deardorff, Alan, (1992); "Welfare Effects of Global Patent Protection," Economica, 59, $35-51$.

[8] Economist, The (2009); "Smother of Invention " Published in the print edition on July 23rd, 2009. Available online at http://www.economist.com/node/14105584.

[9] Economist, The (2012); "Apple v Samsung: Swipe, Pinch and Zoom to the Courtroom." Published in the print edition on September 1st, 2012. Available online at http://www.economist.com/node/21561912.

[10] Gilbert, Richard, and Carl Shapiro (1990); "Optimal Patent Length and Breadth." Rand Journal of Economics, 21 (Spring): 106-12.

[11] Grossman, Gene and Edwin Lai (2004); "International Protection of Intellectual Property." American Economic Review, 94 (5), 1635-53.

[12] Guberman, A., and C. Corman (2000); "Generic Substitution for Brand Name Antiepileptic Drugs: A Survey." Canadian Journal of Neurological Science, 27: 37-43. 
[13] Hatter, John (1994), " "The Doctrine of Equivalents in Patent Litigation: An Analysis of the Epilady Controversy," Indiana International and Comparative Law Review, 5(2), 461-494.

[14] Kasselheim, A.S., A.S. Misono, J.L. Lee, M.R. Stedman, A.M. Brookheart, N.K. Choudhry, and Shrank, W.H. (2008); "Clinical Equivalence of Generic and Brand-Name Drugs Used in Cardiovascular Disease: A Systematic Review and Meta-analysis." Journal of the American Medical Association, 300(21): 2514-2526.

[15] Klemperer, P. (1990); "How Broad Should the Scope of Patent Protection Be?" Rand Journal of Economics, 21 (Spring): 113-30.

[16] Loury, G.C. (1979); "Market structure and innovation." Quarterly Journal of Economics, 93: $395-410$.

[17] Macedo, C. (2009); "Infringement of Product by Process Claims in US Clarified." Journal of Intellectual Property Law and Practice, https://www.arelaw.com/publications/view/productbyprocess/print/

[18] Maskus, Keith E. and Christine McDaniel (1999); "Impact of the Japanese Patent System on Productivity Growth," Japan and the World Economy, 11:557-74.

[19] New York Times, The (2012); "In Japan, a Setback for Apple in Patent Fight." Published in the print edition on August 31st 2012. Also available online at http://www.nytimes.com/2012/09/01/technology/in-japan-a-setback-for-apples-patentfight.html?_r=1\&emc=eta1.

[20] Nordhaus, William D. 1969. Invention, Growth, and Welfare: A Theoretical Treatment of Technological Change. Cambridge, MA: MIT Press.

[21] O'Donoghue, Ted, Suzanne Scotchmer, and Jacques-Francois Thisse (1998) "Patent Breadth, Patent Life, and the Pace of Technological Progress." Journal of Economics and Management Strategy, 7 (Spring): 1-32.

[22] Ralston, W.T. (2007); "Foreign Equivalents of the U.S. Doctrine of Equivalents: We're Playing in the Same Key But it's Not Quite Harmony." Chicago-Kent Journal of Intellectual Property, 6: 178-197. 
[23] Reinganum, J. (1982); "A Dynamic Game of R\&D: Patent Protection and Competitive Behavior." Econometrica, 50 671-688.

[24] Schiff, E., (1971); Industrialization without National Patents: The Netherlands, 1869-1912, Switzerland, 1850-190\%. Princeton, NJ: Princeton University Press. 